\title{
The Regime-switching volatility of Euro Area Business Cycles
}

Stéphane Lhuissier

Highlights

I From the early 1990 s to the onset of the Great Recession in 2008 , the volatility of business cycle fluctuations in the euro area declined from the high levels of prior eras.

- This period of "Great Moderation" appears to be due to smaller economic shocks, which were mostly associated to productivity and marginal efficiency of investment.

- These investment shocks, which affect the efficiency of the system of financial intermediation to transform savings into real capital, can be interpreted as an indicator of credit conditions in the euro area. 


\section{Abstract}

We document the strong evidence of time variation in the volatility of euro area business cycles since 1970. Then, we provide the quantitative sources of these changes by using a medium-scale DSGE model allowing time variation in structural disturbance variances. We show that: 1) The size of different types of shock oscillates, in a synchronized manner, between two regimes over time, with the high-volatility regime prevailing predominantly in the 1970s, sporadically in the 1980s and 1990s, and during the Great Recession. 2) Their relative importance remains, however, unchanged across regimes, where neutral technology shocks and marginal efficiency of investment shocks are the dominant sources of business cycle fluctuations; and 3) These investment shocks, which affect the transformation of savings into productive capital, can be interpreted as an indicator of credit condtions.

\section{Keywords}

Business Cycles, DSGE, Euro Area, Heteroskedasticity, Markov-switching.

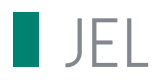

C11, C51, E32, E42, E52.

\section{Working Paper}

\section{CEPI}

CEPII (Centre d'Etudes Prospectives et d'Informations Internationales) is a French institute dedicated to producing independent, policyoriented economic research helpful to understand the international economic environment and challenges in the areas of trade policy, competitiveness, macroeconomics, international finance and growth
CEPII Working Paper

Contributing to research in international economics

C C CEPII, PARIS, 2015

All rights reserved. Opinions expressed in this publication are those of the author(s) alone.

$\begin{array}{ll}\text { Editorial Director: } & \text { CEPII } \\ \text { Sébastien Jean } & \begin{array}{l}113, \text { rue de Grenelle } \\ 75007 \text { Paris }\end{array} \\ \text { Production: } & +33153685500 \\ \text { Laure Boivin } & \text { www.cepii.fr } \\ \text { No ISSN: } 1293-2574 & \text { Press contact: presse@ }\end{array}$




\title{
The Regime-switching volatility of Euro Area Business Cycles
}

\author{
Stéphane Lhuissier*
}

\section{Introduction}

There is a long tradition in macroeconomics of investigating the sources of business cycle fluctuations. In the light of this, much has been written about the causes of large and persistent variation in the volatility of U.S. macroeconomic time series over the past four decades. By contrast, empirical research has shown little interest in investigating this phenomenon in the euro area business cycles. Yet, a better understanding of the causes of the rises and falls of volatility is essential to policymakers when making their decisions in the conduct of monetary and fiscal policy to both eliminate times of long-lasting high-volatility and set up defenses against the threat of higher volatility.

The purpose of the paper is twofold. The first is to document the empirical evidence of time-varying volatility in major business-cycle components in the euro area since 1970 . We postulate a regime-switching univariate process for the volatility of each of major businesscycle components using Bayesian methods. One conclusion is that, from the early 1990s to the onset of the Great Recession in 2008, the volatility of euro area business cycles declined from the high levels of prior eras.

Our second objective is to provide the quantitative sources of these changes. To do so, we employ a variety of medium-scale Dynamic Stochastic General Equilibrium (DSGE) models in which structural disturbance variances are allowed to change over time according to a Markov-switching process. We find that structural shocks hitting the euro area economy have been characterized by switches between a low- and a high-volatility regime over time, where regime changes in the volatilities of structural shocks are synchronized. In particular, the high-volatility regime was in place for a large part of the 1970s, early 1980s, the 1990s and during the Great Recession in 2008-2009. In addition, we examine the relative

\footnotetext{
*CEPII, (I am deeply indebted to Michel Juillard and Tao Zha for their guidance and advice. I also thank Jean-Guillaume Sahuc and participants at several seminars for their helpful comments. This paper is a revised version of the second chapter of my Ph.D. thesis. It previously circulated as 'Heteroskedastic Shocks and the Great Moderation in the Euro Area'. Email: stephane Ihuissier@club.fr; URL: http://www.stephanelhuissier.eu).
} 
importance of sources of fluctuations and show that two types of shocks appear to be the most important in explaining the macroeconomic fluctuations of the euro area, namely neutral technology shocks and shocks to the marginal efficiency of investment (MEI). Although the size of these shocks differ between the two synchronized shock regimes, their relative importance remains unchanged. Taken together, they account for more than half of output variation under both regimes.

Because of its relative importance in explaining fluctuations, we attempt to provide a structural interpretation of MEI shocks. More specifically, we provide evidence that MEI shocks stem from disturbances in the functioning of the financial system and, more precisely, from exogenous changes in the effective cost of credit access. Following Justiniano, Primiceri, and Tambalotti (2011), our interpretation lies in the fact this shock affects the efficiency at which the investment goods are transformed into the production of installed capital or, more broadly, the efficiency of the system of financial intermediation to transform mobilized savings from depositors (i.e. households) into real capital. Efficient financial intermediation implies, for example, a reduction of the cost of transferring funds from savers to investors, who ultimately convert them into productive capital. To prove our case, we show that MEI shocks are remarkably well correlated with the constructed non-financial corporations credit spread by Gilchrist and Mojon (2014), an indicator of credit tightening in the euro area.

The analytical framework of this paper may be potentially problematic as it may not identify the correct source of time variation. Indeed, it may be that the greater economic stability observed during the last two decades was the result of improved monetary policy (i.e., more aggressive policy responses to inflation) due to the process of the creation of European Monetary Union (EMU) rather than smaller structural disturbances as stated in this paper. As a robustness check, we prove that our overall results turn out to be unchanged when considering the possibility of improved monetary policy from the last two decades. This trend toward greater stability is, therefore, largely the result of "smaller" shocks rather than improved monetary policy.

Finally, the version of the Markov-switching DSGE model we choose for obtaining the overall results has been selected among numerous versions of the DSGE model using Bayesian methods. All versions of the DSGE model consider the same microeconomic foundations along the lines of Christiano, Eichenbaum, and Evans (2005) and Smets and Wouters (2007); namely, a number of real and nominal frictions, as well as structural shocks that give economic interpretations. What changes across the versions of the model is only the number of regimes in shock variances. We compare the fit of these alternative 
models by performing Bayesian posterior odds ratios. Clearly, the best-fit model is the synchronized two-states model. All other versions of the model, including the constantparameters model in which the variances of shocks remain constant over time, do not fit to the data as well as the best-fitting model.

Literature review. As previously mentioned, the literature almost exclusively focused on the variability of U.S. volatility, and in particular on the causes of the "Great Moderation", a term referring to a large decline in the U.S. macroeconomic volatility in the mid1980s. There are usually two types of explanations. On one hand, the large decline of key macroeconomic variables is attributed to smaller structural shocks than those previously experienced. Among others, see Fisher (2006), Justiniano and Primiceri (2008), Smets and Wouters (2007), and Liu, Waggoner, and Zha (2011). On the other hand, Clarida, Gali, and Gertler (2000) and Lubik and Schorfheide (2004) find that drastic changes in monetary policy are the main cause of changes in macroeconomic volatility. Clearly, our results corroborate with the former.

The rare papers that focus on the euro area include Cecioni and Neri (2011) and AvouyiDovi and Sahuc (2013). Splitting their sample in 1999, they find that the post-euro period has produced macroeconomic shocks smaller than those experienced in the pre-euro period. The limit of their analysis is that they split the sample according to "a prior" whereas the changing dynamics of the economy are, in general, hidden and thus unobservable. In addition to that, all of these previous works on the euro area exclude any time variations in the volatility of structural shocks and thus cannot provide the contribution of each shock to the range of variables over time. The methodology employed in this paper overcomes this difficulty by dealing with the entire sample and letting the data "choose" when regime shifts in shock variances occur.

From a methodological standpoint, this paper is related to an increasing literature dealing with heteroskedastic shocks in vector autoregressions. This literature includes Bernanke and Mihov (1998), Cogley and Sargent (2005), Primiceri (2005), Sims and Zha (2006), and Canova, Gambetti, and Pappa (2008). In contrast to this literature, Justiniano and Primiceri (2008) and Liu, Waggoner, and Zha (2011) allow for heteroskedastic shocks in a richly-parameterized DSGE model, which provide economic interpretations of each shock. In this respect, the Liu, Waggoner, and Zha (2011) specification is closest to our benchmark specification; namely, allowing for each structural disturbance to vary over time according to a Markov-switching process in a DSGE model. The focus of the two papers is, however, clearly different: we apply the methodology to the euro area macroeconomic time series, whose the sample size is now large enough to explore macroeconomic dy- 
namics in the euro area. Moreover, the euro area is particularly interesting given that the characteristics of its business cycles fundamentally differ from those in the United States. ${ }^{1}$ There is, therefore, no reason to believe that certain interpretations of facts are robust across countries.

More recently, following the work of Bianchi (2013), an increasing literature embeds both Markov-switching changes in the conduct of policy and heteroskedasticity in DSGE models to study the variability of macroeconomic fluctuations [Davig and Doh (2013), Bianchi and Ilut (2014), and Lhuissier and Zabelina (2015)]. Interestingly, our results seem to be in line with Bianchi (2013) who find that while the estimates support the possibility of changes in monetary policy, these are not enough to explain the substantial reduction in macroeconomic volatility. Note, however, that we allow for deterministic and irreversible changes in the behavior of the central bank whereas in Bianchi (2013), regime switches are modeled as stochastic and reversible.

This paper proceeds as follows: Section 2 documents changes in volatility over the past forty years. Section 3 provides the theoretical microfoundations-based model. Section 4 compares the fit of a number of Markov-switching DSGEs, selects the best-fit model, and provides the posterior estimates of this model. Section 5 discusses the economic implications of the best-fit model. Section 6 provides a structural interpretation of the shock to the marginal efficiency of investment. Section 7 discusses robustness by examining whether results remain unchanged when monetary policy is allowed to change over time. Section 8 concludes.

\section{Some Reduced-form Statistics}

This section documents changes in volatility throughout the euro area economy over the past forty years by employing a method designed to describe time-varying macroeconomic time series processes.

\subsection{Data and transformations}

We consider data on eight quarterly macroeconomic time series from 1970.Q2 to 2012.Q1. All of them are major business-cycle components commonly used in macroeconomic models. All data are extracted from the AWM database compiled by Fagan, Henry, and Mestre

\footnotetext{
${ }^{1}$ See, for example, Sahuc and Smets (2008).
} 
$(2005)^{2}$, except for hours worked: Real GDP (YER), real consumption (PCR), real investment (ITR), real wages constructed by dividing nominal wages (WRN) by the GDP deflator (YED), prices (YED), the short-term (3-months) nominal interest rate (STN) ${ }^{3}$, and the relative price of investment obtained by dividing the investment deflator (ITD) by the consumption deflator (PCD). Total hours worked is constructed by averaging the series for France, Germany, and Italy from the database of Ohanian and Raffo (2012).

We transform these quarterly data to eliminate trends and induce stationarity. Specifically, real variables and total hours ${ }^{4}$ are expressed in growth rates, prices were expressed in inflation rates, and the interest rate keeps unchanged. All data are displayed in Figure C.1.

\subsection{Evidence of changes in volatility}

We allow the variance of the growth rate in each macroeconomic time series to be evolving according to a two-state Markov switching, thus allowing to identify two distinct regimes: a high-volatility regime and a low-volatility regime. The two-states volatility model is as follows

$$
\begin{aligned}
\Delta y_{t} & =\rho \Delta y_{t-1}+\sigma\left(s_{t}\right) \varepsilon_{t}, & & t=1, \cdots, T \\
p_{i, j} & =\operatorname{Pr}\left(s_{t}=i \mid s_{t-1}=j\right), & & i, j=1,2
\end{aligned}
$$

with $\Delta y_{t}$ is the stationary variable, $\rho$ is the parameter of persistence; $\sigma\left(s_{t}\right)$ is the conditional variance where the discrete and unobserved variable $s_{t}$ is an exogenous first-order Markov process; and $\mathrm{T}$ is the sample size.

We estimate the parameters of the process in equation (1) and (2) with Bayesian methods. More specifically, we follow Kim and Nelson (1999) to inference by employing a Gibbssampling procedure to alternately sample from the conditional distributions.

We now elicit our priors. For $\rho$ we choose a Normal prior with mean 0.60 and a large standard deviation 0.20. For $\sigma$, we pick an Inverse-gamma distribution with $a=0.3261$

\footnotetext{
${ }^{2}$ The Euro Area Business Cycle Network regularly updates these macro series and makes it available on http://www.eabcn.org/area-wide-model.

${ }^{3}$ The short-term (3-months) nominal interest rate has been constructed as a weighted average of the national interbank (3-months) short-term interest rates, from 1970 to 1993. Post-1994 the nominal interest rate is the quarterly EURIBOR 3-month. Although there have been no single monetary authority for the euro area from 1970 to the late 1990s, Clarida, Gali, and Gertler (1998) and Angeloni, Kashyap, and Mojon (2003) show that the way policy was conducted across euro area countries has not been so different over this period, reinforcing the use of a single interest rate.

${ }^{4}$ Total hours were transformed to growth rates because it exhibits a trend within sample.
} 
and $b=0.0145$ as hyperparameters. Finally, the prior duration of each regime is about eleven quarters, meaning that the average probability of staying in the same regime is equal to 0.90 and a standard deviation equal to 0.06 . Overall, our priors are enough loose to let the data, through the likelihood, dominate the posterior distribution. Our results are robust to change in the standard deviation of the priors.

The resulting estimated parameters ${ }^{5}$ for the eight macroeconomic time series are reported in Table C.1. We report the median as well as the 90 percent error bands associated with each parameter. The first finding that is evident is the drastic difference in estimated innovations across the two states. For each column (i.e each series), the first state (third row) gives modest sizes to $\sigma$ relatively to the second state (fourth row), in which the size of innovations are up to 10 times larger. For obvious reasons, we label "Regime 1" as the low-volatility regime and "Regime 2 " as the high-volatility regime. For example, in the first column (GDP growth rates), the posterior median of the standard deviations of the shock under "Regime 1", is $\sigma\left(s_{t}=1\right)=0.64$, while under "Regime 2 " it is much lower, $\sigma\left(s_{t}=2\right)=0.10$. This result does generalize to the seven other time series. For all of them, The tight interval probabilities reinforce the estimated median values.

Regarding the posterior probabilities (the first two rows in the table), it is apparent that the persistence of staying in each state is very high. For GDP growth rates, the bounds for the $p_{11}$ values in the $90 \%$ probability interval are respectively 0.81 and 0.96 , and those for $p_{22}$ are 0.87 and 0.97 . More generally, the posterior is tightly concentrated for most series.

Regarding the persistence parameter, the estimated value for each series differs substantially across series. We can, however, make the distinction between two categories. On one hand, the "low-persistence" variables including output growth ( $\rho=0.49)$, Consumption growth $(\rho=0.12)$, Investment growth $(\rho=0.34)$, Hours $(\rho=0.37)$ and the relative price of investment $(\rho=0.34)$. On the other hand, the "high-persistence" variables consisting of wages growth $(\rho=0.89)$, inflation $(\rho=0.93)$, and the nominal interest rate $(\rho=0.99)$, revealing a large degree of persistence in each regime.

As a robustness check, we have also estimated the eight models by letting the persistence parameters, $\rho$, and the shock variances to switch, in a synchronized manner, over time. Clearly, the persistence remains unchanged across regimes. Moreover, we have shown the large persistence of each regime over time. This persistence may be due to the fact that

\footnotetext{
${ }^{5}$ We draw 11,000 times from the posterior of each of the eight models that we estimate. The first 1,000 are discarded.
} 
the prior about the average duration of each regime is about 10 quarters. Several other prior durations were examined to determine if they deliver different outcomes. However, the changes in prior duration do not affect the main conclusions.

Figure C.2 shows the estimated probabilities of the high-volatility regime over time produced by each autoregressive model. The probabilities are smoothed in the sense of Kim (1994); i.e., full sample information is used in getting the regime probabilities at each date. Two main results emerge from this figure. First, there are repeated fluctuations between the two regimes of volatility. Second, when looking at all panels, it is apparent that regime changes are not synchronized.

We now examine the historical path of estimated probabilities for each series in particular. We start with output growth. Clearly, from 1970 to the early 1990s, the high-volatility regime has been the dominant regime. Then, from the mid-1990s, and more precisely in 1993, the probability of being in the low-volatility regime was equal or close to one. We could name this phenomenon as the "European Great Moderation". This trend toward greater stability has been, however, reversed following the Great Recession in 2008. Interestingly, we do not observe a large decline in the macroeconomic volatility in 1984 as experienced in the United States. The times of volatility changes in the nominal interest rate is remarkably similar to the times of changes in output growth. For wages and consumption growth, the pattern is somewhat similar with the exception of the recent financial crisis, which is covered by a low-volatility regime. Note, however, that since 2010, the volatility of consumption growth is identified as high. We turn now to investment growth. Surprisingly, the high-volatility regime is the dominant regime throughout the sample, except for the period from the early 2000s to the mid-2000s. By contrast, the low-volatility regime has been in place for a large part of the sample for inflation and the relative price of investment. For both series, we do not observe any regime changes triggered by the recent financial crisis. Finally, it seems that the volatility of hours worked growth encounters difficulties in switching between regimes.

To sum up, most of our quarterly data suggests a large decline in the macroeconomic volatility from the early or the end of 1990s. The decline of the volatility of inflation and the relative price of investment began at a much earlier stage, i.e. in the end of 1970s and the mid-1980s. In addition to that, the recent financial crisis has been characterized mainly by the high-volatility regime.

Giving these findings, we move to use a medium-scale DSGE model to provide quantitative sources of changes in volatility that we find in major macroeconomic time series. 


\section{The model}

Following Christiano, Eichenbaum, and Evans (2005) and Smets and Wouters (2007), the DSGE model considers many features that are commonly used in the literature, such as habit formation in consumption, sticky wage and price setting à la Calvo (1983), and a unit root in the technology growth process.

In addition, we closely follow Justiniano, Primiceri, and Tambalotti (2011) and augment the standard model in two ways. First, we allow for non-stationary investment-specific technological progress. Second, the process of capital accumulation can be affected by two shocks: an investment-specific technology (IST) shock which affects the transformation of consumption into investment goods, and a shocks to the marginal efficiency of investment affecting the transformation of investment into capital goods. The model consists, therefore, of six classes of agents: households, consumption good producing firms, investment good producing firms, capital good producing firms, employment agencies, and a government. The model is symmetric across each agent, thus allowing us to concentrate on an analysis of representative agents. Six other structural shocks are added to the two above-mentioned shocks: technology shock, shock to the household preferences, price markup shock, wage markup shock, government spending shock, and monetary policy shock. The log-linearization is discussed in Appendix A.

\subsection{Households}

There is a continuum of households, indexed by $j \in[0,1]$. Each household maximizes their expected utility

$$
\mathrm{E}_{t} \sum_{s=0}^{\infty} \beta^{s} b_{t+s}\left[\ln \left(C_{t+s}-h C_{t+s-1}\right)-\varphi \frac{L_{t+s}(i)^{1+\nu}}{1+\nu}\right]
$$

where $C_{t}$ is consumption, $L_{t}$ is labor, $h$ is the degree of habit formation, $\beta \in(0,1)$ is the discount factor, and $\nu \geq 0$ is the inverse Frisch elasticity of labor supply. The disturbance of the discount factor $b_{t}$, known as intertemporal preference, follows an autoregressive process

$$
\ln \left(b_{t}\right)=\rho_{b} \ln \left(b_{t-1}\right)+\varepsilon_{b, t},
$$

where the distribution for $\varepsilon_{b, t}$ is

$$
\operatorname{normal}\left(\varepsilon_{b, t} \mid 0, \sigma_{b}^{2}\right) \text {, }
$$

where normal $(x \mid \mu, \Sigma)$ denotes the normal distribution of $x$ with mean $\mu$ and variance $\Sigma$. 
The expected utility is subject to the budget constraint as follows:

$$
P_{t} C_{t}+P_{k t} i_{t}+T_{t}+B_{t} \geq R_{t-1} B_{t-1}+Q_{t}(j)+\Pi_{t}+W_{t}(j) L_{t}(j)+r_{t}^{k} u_{t} \bar{K}_{t-1}-P_{t} \frac{a\left(u_{t}\right)}{\Upsilon_{t}} \bar{K}_{t-1}
$$

where $T_{t}$ are lump-sum taxes, $B_{t}$ denotes the holding of government bonds, $R_{t}$ is the nominal interest rate, $Q_{t}(j)$ is the amount of net cash flow from a portfolio of contingent securities, $\Pi$ is units of profit from owning the firms, and the variable $\Upsilon_{t}$ represents investment-specific technological progress.

Households have capital and choose the capital utilization rate $u_{t}$, thus transforming physical capital $\left(\bar{K}_{t}\right)$ into effective capital $\left(K_{t}\right)$ as follows:

$$
K_{t}=u_{t} \bar{K}_{t-1}
$$

Effective capital is then rented to firms at the rate $r_{t}^{k}$. The capital utilization cost is $P_{t} \frac{a\left(u_{t}\right)}{\Upsilon_{t}}$ per unit of physical capital. In a steady state, we follow Altig, Christiano, Eichenbaum, and Linde (2011) and assume that $u=1, a(1)=0$, and $\chi=a^{\prime \prime}(1) / a^{\prime}(1)$. The physical capital accumulates according to the following rule:

$$
\bar{K}_{t}=(1-\delta) \bar{K}_{t-1}+i_{t}
$$

with $\delta$ being the depreciation rate.

Following Erceg, Henderson, and Levin (2000), the wages are sticky. At each period, only a fraction $\left(1-\xi_{w}\right)$ of households can adjust wages by maximizing

$$
E_{t}=\left\{\sum_{s=0}^{\infty} \xi_{w}^{s} \beta^{s}\left[-b_{t+s} \varphi \frac{L_{t+s}(j)^{1+\nu}}{1+\nu}+\Lambda_{t+s} W_{t}(j) L_{t+s}(j)\right]\right\},
$$

where $W_{t}(j)$ is the optimal wage. The remaining households index their wages following the rule

$$
W_{t}(j)=W_{t-1}(j)\left(\pi_{t-1} e^{z_{t}-1}\right)^{\iota_{w}}\left(\pi e^{\gamma}\right)^{1-\iota_{w}}
$$

\subsection{Consumption good producers}

In order to produce the final consumption good, we assume the process goes through a chain of intermediate and final good producers.

\subsubsection{Final good producers}

At each period $t$, firms buy $Y_{t}(i)$ units of intermediate good $i$ at nominal price $P_{t}(i)$ and combine these intermediate goods into $Y_{t}$ units of finished goods according to technology 


$$
Y_{t}=\left[\int_{0}^{1} Y_{t}(i)^{\frac{1}{1+\lambda_{p, t}}} d i\right]^{1+\lambda_{p, t}},
$$

where the price markup shock, denoted $\lambda_{p, t}$, follows a stochastic process as follows:

$$
\ln \lambda_{p, t}=\left(1-\rho_{p}\right) \ln \lambda_{p}+\rho_{p} \ln \lambda_{p, t-1}=\varepsilon_{p, t}-\theta_{p} \varepsilon_{p, t-1}
$$

with $\varepsilon_{p, t}$ having the following distribution:

$$
\operatorname{normal}\left(\varepsilon_{p, t} \mid 0, \sigma_{p}^{2}\right) \text {. }
$$

The zero profit condition and profit maximization allow us to use the price of final good $P_{t}$ as a CES aggregate of the prices of the intermediate goods $P_{t}(i)$ :

$$
P_{t}=\left[\int_{0}^{1} P_{t}(i)^{\frac{1}{\lambda_{p, t}}} d i\right]^{\lambda_{p, t}},
$$

and the demand function for the intermediate good $i$ is

$$
Y_{t}(i)=\left(\frac{P_{t}(i)}{P_{t}}\right)^{-\frac{1+\lambda_{p, t}}{\lambda_{p, t}}} Y_{t}
$$

\subsubsection{Intermediate good producers}

A monopolistically-competitive firm produces differentiated consumption good $i$ according to the following production function

$$
Y_{t}(i)=\max \left\{A_{t}^{1-\alpha} K_{t}(i)^{\alpha} L_{t}(i)^{1-\alpha}-A_{t} \Upsilon_{t}^{\frac{\alpha}{1-\alpha}} F ; 0\right\}
$$

where $K_{t}(i)$ and $L_{t}(i)$ refer to the amounts of capital and labor employed by firm $i$ and $A_{t}$ denotes the neutral technology shock following a unit root process with a growth rate $z_{t} \equiv \ln \left(A_{t} / A_{t-1}\right)$, such as

$$
z_{t}=\left(1-\rho_{z}\right) \gamma+\rho_{z} z_{t-1}+\varepsilon_{z t}
$$

where the distribution for $\varepsilon_{z, t}$ is

$$
\operatorname{normal}\left(\varepsilon_{z, t} \mid 0, \sigma_{z}^{2}\right) \text {. }
$$

$F$ is a fixed cost of production ensuring that steady state profits are zero. See Christiano, Eichenbaum, and Evans (2005). 
Following Calvo (1983), each firm sets prices according to a staggering mechanism. For each period, a fraction $\theta_{p}$ of firms cannot re-optimize its prices optimally and indexes them according to the rule

$$
P_{t}(i)=\pi^{1-\iota_{p}} \pi_{t-1}^{\iota_{p}} P_{t-1}(i)
$$

where $\pi_{t}=P_{t} / P_{t-1}$ is gross inflation and $\pi$ is its steady state. The other remaining fraction of firms chooses its prices $P_{t}(i)$ by maximizing the present value of futures profits

$$
\mathrm{E}_{t}\left\{\sum_{s=0}^{\infty}\left(\beta \xi_{p}\right)^{s} \frac{\lambda_{t+s}}{\Lambda_{t}}\left[P_{t}(i)\left(\prod_{k=1}^{s} \pi_{t+k-1}^{\iota_{p}} \pi^{1-\iota_{p}}\right) Y_{t+s}(i)-W_{t+s} L_{t+s}(i)-r_{t+1}^{k} K_{t+s}(i)\right]\right\}
$$

where $\lambda_{t}$ is the marginal utility of nominal income.

\subsection{Investment good producers}

Each investment good producer maximizes their expected utility

$$
P_{\mid t} I_{t}-P_{t} Y_{t}^{\prime}
$$

subject to the production technology

$$
I_{t}=\Upsilon_{t} Y_{t}^{\prime}
$$

where $Y_{t}^{\prime}$ are the purchase units of final good to transform them into investment goods $I_{t}$. Finally, they sell their investment goods to capital producers at a unit price $P_{I t}$. Profit maximization implies that the price of investment goods relative to the price of consumption goods is equal to the inverse of the IST shock

$$
\frac{P_{l t}}{P_{t}}=\Upsilon^{-1}
$$

The variable $\Upsilon_{t}$ denotes the investment-specific technological shock and follows a unit root process with a growth rate $v_{t}=\ln \left(\Upsilon_{t} / \Upsilon_{t-1}\right)$, such as

$$
v_{t}=\left(1-\rho_{v}\right) \gamma_{v}+\rho_{v} v_{t-1}+\varepsilon_{v, t},
$$

with the distribution for $\varepsilon_{v, t}$ is

$$
\operatorname{normal}\left(\varepsilon_{v, t} \mid 0, \sigma_{v}^{2}\right) \text {. }
$$




\subsection{Capital good producers}

These perfectly competitive firms buy investment goods and transform them into installed capital, which is sold to households. The production of new capital, $i_{t}$, is as follows

$$
i_{t}=\mu_{t}\left(1-S\left(\frac{I_{t}}{I_{t-1}}\right)\right) I_{t}
$$

with the function $S$ corresponding to the presence of adjustment costs in investment with $S=S^{\prime}=0$ and $S^{\prime \prime}>0$ in steady state. The investment shock $\mu_{t}$ is responsible for changes in efficiency with which final goods are transformed into physical capital. We refer to this shock as marginal efficiency of investment (MEI). The shock follows an $A R(1)$ process in the following way:

$$
\ln \mu_{t}=\rho_{\mu} \ln \mu_{t-1}+\varepsilon_{\mu, t},
$$

where the distribution for $\varepsilon_{\mu, t}$ is

$$
\operatorname{normal}\left(\varepsilon_{\mu, t} \mid 0, \sigma_{\mu}^{2}\right) \text {. }
$$

Capital good producers maximize the expected discounted value of future profits as follows

$$
\mathrm{E}_{t} \sum_{s=0}^{\infty} \beta^{s} \lambda_{t+s}\left[P_{k t+s} i_{t+s}-P_{l t+s} l_{t+s}\right],
$$

where $P_{k t}$ represents the price of installed capital per efficiency unit.

\subsection{Employment agencies}

Employment agencies are owned by a continuum of households $j \in[0,1]$. Intermediate firms buy homogenous labor from employment agencies. Homogenous labor is an aggregate of specialized labor, supplied by households, in the following way:

$$
L_{t}=\left[\int_{0}^{1} L_{t}(j)^{\frac{1}{1+\lambda_{w, t}}} d j\right]^{1+\lambda_{w, t}},
$$

where $\lambda_{w, t}$ is a wage markup shock. It follows the stochastic process

$$
\ln \left(1+\lambda_{w, t}\right)=\left(1-\rho_{w}\right) \ln \left(1+\lambda_{w}\right)+\rho_{w} \ln \left(1+\lambda_{w, t-1}\right)=\varepsilon_{w, t}-\theta_{w} \varepsilon_{w, t-1}
$$

with $\varepsilon_{w, t}$ following the distribution

$$
\operatorname{normal}\left(\varepsilon_{w, t} \mid 0, \sigma_{w}^{2}\right)
$$

The labor demand function takes the following form:

$$
L_{t}(j)=\left(\frac{W_{t}(i)}{W_{t}}\right)^{-\frac{1+\lambda_{w, t}}{\lambda_{w, t}}} L_{t}
$$


where employment agencies pay $W(j)$ for this differentiated input to the supplier of labor of type $j$. Finally, the intermediate goods producers aggregate wages and pay $W_{t}$, defined as:

$$
W_{t}=\left[\int_{0}^{1} W_{t}(j)^{\frac{1}{\lambda_{w, t}}} d j\right]^{\lambda_{w, t}}
$$

\subsection{The government}

Monetary authority responds to deviations in inflation as well as to the level and the growth rate of the GDP gap, GDP $/ G D P_{t}^{*}$, according to the following rule:

$$
\frac{R_{t}}{R}=\left(\frac{R_{t}}{R}\right)^{\rho_{R}}\left[\left(\frac{\pi_{t}}{\pi}\right)^{\psi_{\pi}}\left(\frac{G D P_{t}}{G D P_{t}^{*}}\right)^{\psi_{x}}\right]^{1-\rho_{R}}\left[\frac{G D P_{t} / G D P_{t-1}}{G D P_{t}^{*} / G D P_{t-1}^{*}}\right]^{\psi_{d x}} \eta_{m p, t},
$$

where $G D P_{t}^{*}$ is the potential output (i.e economy with flexible price and wage levels). The GDP, denoted $G D P_{t}$, is defined as $C_{t}+I_{t}+G_{t}$. The monetary policy shock $\eta_{m p, t}$ evolves according to

$$
\ln \eta_{m p, t}=\rho_{m p} \ln \eta_{m p, t-1}+\varepsilon_{m p, t}
$$

where the distribution for $\varepsilon_{m p, t}$ is

$$
\operatorname{normal}\left(\varepsilon_{m p, t} \mid 0, \sigma_{m p}^{2}\right) \text {. }
$$

The government issues short-term bonds to finance its budget deficit. Public spending, denoted $G_{t}$, is determined exogenously and depends on a fraction of output

$$
G_{t}=\left(1-\frac{1}{g_{t}}\right) Y_{t}
$$

where $g_{t}$ is the government spending shock evolving as

$$
\ln g_{t}=\left(1-\rho_{g}\right) \operatorname{lng}+\rho_{g} \ln g_{t-1}+\varepsilon_{g, t}
$$

where the distribution for $\varepsilon_{g, t}$ is

$$
\operatorname{normal}\left(\varepsilon_{g, t} \mid 0, \sigma_{g}^{2}\right) \text {. }
$$

\subsection{Changes in shock variances}

We allow explicitly for changes in the stochastic volatility of the DSGE model. Basically, what changes across the versions of the DSGE model is only the number of regimes in structural shock variances. That is, we allow the possibility of changes in the sources of business cycle fluctuations over time. To do so, we follow Liu, Waggoner, and Zha (2011) by employing a Markov-switching process in the variances of structural disturbances. 


\section{Empirical results}

This section provides the main quantitative results. First, we compare the fit of alternative models in section 4.1. Second, we choose the best-performing model and report the estimates of structural parameters in section 4.2. DSGE models are estimated from 1970.Q2 to 2012.Q1 ${ }^{6}$ The strategy of estimation is described in Appendix B.

\subsection{Comparing the fit of alternative models}

We compute the marginal data densities (MDDs) of different versions of the DSGE model to discriminate between them. The MDDs are computed by using the Bridge sampling method proposed by Meng and Wong (1996), where the Markov Chain Monte Carlo sample is combined with a sample from an importance density. It has been demonstrated by Fruhwirth-Schnatter (2004) that such a methodology is particularly robust and efficient to compute the marginal likelihood of mixture models, such as Markov-switching models.

Table C.2 reports the log values of MDDs. One can see from this table that the best-fit model is the one that allows shock variances to vary across two regimes $\left(\mathfrak{M}_{2 v}\right)$. Clearly, it outperforms the constant-parameter DSGE model $\left(\mathfrak{M}_{\text {constant }}\right)$. The log MDD for $\mathfrak{M}_{2 v}$ is -869.42, compared to -927.17 for the $\mathfrak{M}_{\text {constant }}$ model.

We have also considered models in which only a subset of shock variances can change over time. More specifically, we have looked at models where only the variance of the MEI shock follows a Markov-switching process $\left(\mathfrak{M}_{2 \mathrm{MEI}-\mathrm{v}}\right)$, and also where only the variances of the neutral and investment-specific technology shocks follow a Markov-switching process $\left(\mathfrak{M}_{2 \text { Tech-v }}\right)$. Looking at the fourth and fifth rows of the table, none of these models outperforms $\mathfrak{M}_{2 v}$.

The estimated MDD for the $\mathfrak{M}_{3 v}$ model that allows three regimes in shock variances is erratic, meaning that there are some redundant states. In particular, we observe that a state did not occur at all in the sample, implying a level of MDD much lower than those reported for the other models (see Sims and Zha (2006) for details). Thus, we prefer displaying "***" for this case rather than a specific number.

Overall, these results are robust to different MDD methods; in particular, to the Geweke (1999) and Sims, Waggoner, and Zha (2008) methods. Although their MDDs are not reported, the best of the models is still the one with synchronized shifts in shock variances

\footnotetext{
${ }^{6}$ We do not include the post-2012.Q2 period to avoid the issue of the zero lower bound.
} 
across two regimes. In the rest of the paper, we devote our attention to this two-regimes volatility model.

\subsection{The posterior distribution}

Tables C. 3 and C.4 report the posterior median with a 90 percent probability interval for the structural parameters and shock processes of the $\mathfrak{M}_{2 v}$ model. Figure C.3 displays the prior (dotted green line) and posterior (solid black line) distributions for some key parameters.

Several parameters deserve comments. The estimate for $100(\pi-1)$ is 1.20 , implying an annual inflation rate of the economy around 4.80 percent. The estimate for the steadystate composite technology growth rate $\left(\gamma^{*}\right)$ is 0.33 , which implies a growth rate of the economy of 1.32 percent per annum. ${ }^{7}$ This is in line with the value reported by Sahuc and Smets (2008).

Regarding the parameters that determine the degree of nominal rigidity, the estimates for $\iota_{w}$ and $\iota_{p}$ are 0.06 and 0.16 , respectively, with tight error bands. Indeed, their distributions are sharply peaked relative to the prior distributions (figure C.3). The low values of these parameters, indicating a low degree of indexation to past inflation, are in line with those reported in the literature dealing with the euro area economy. The estimates for $\theta_{w}$ and $\theta_{p}$ are respectively 0.83 and 0.92 with relatively tight error bands. Looking at figure C.3, their posterior distributions are shifted to the right relative to the priors and are remarkably peaked, indicating that the data contains plenty of information about the degree of priceand wage-stickiness. Also, these results imply that the duration of wage and price contracts are about 6 and 12 quarters, respectively. Once again, all of these results are consistent with the existing literature [Sahuc and Smets (2008), Cecioni and Neri (2011), and AvouyiDovi and Sahuc (2013)].

Regarding monetary policy parameters, the estimate for $\psi_{\pi}$, the nominal interest rate response to inflation, is 1.82 with the probability interval $[1.52 ; 2.14]$. The estimates for $\psi_{X}$ and $\psi_{d X}$ are 0.11 and 0.28 , respectively, with their corresponding error bands appearing relatively tight. Our results suggest that the euro area exhibits a high degree of inertia; $\rho_{R}=0.92$ with the corresponding tight error bands $[0.89 ; 0.94]$.

Finally, we discuss the parameters governed by the Markov-switching process, namely the

\footnotetext{
${ }^{7}$ The growth rate of the economy implied by the model is small compared to the sample mean of output growth (an annual value around 1.60 percent). Note, however, that this value corroborates with Sahuc and Smets (2008) and that the 90 percent probability interval covers the actual mean.
} 
shock variances. Two distinct regimes clearly emerge. The first regime emerges as the one in which shock variances are the highest when compared to those in the second regime. For this reason, we label Regime 1 as the "high-volatility" regime and Regime 2 as the "lowvolatility" regime. More specifically, most of the estimated standard deviations for shocks are about twice as high in the "high-volatility" regime. For both regimes, the MEI shocks $\left[\sigma_{\mu}\left(s_{t}\right)\right]$ have the largest variances, while the intertemporal preference shocks $\left[\sigma_{b}\left(s_{t}\right)\right]$ have the lowest variances.

Figure C.4 displays the probabilities — evaluated at the posterior mode - of being in the "high-volatility" regime over time. One can see from the figure that the euro area economy has been characterized by switches between the low- and high-volatility regimes over time. In particular, the high-volatility regime has been predominantly prevailed in the $1970 \mathrm{~s}$, sporadically in the 1980s and 1990s, and during the Great Recession. As a consequence, the timing of the large decline in volatility is different with respect to what happens when regime-switching models or time-varying models are estimated on U.S. data. Actually, most of the existing literature for the U.S. economy finds a drop in shock variances from the early 1980s to explain the U.S. Great Moderation. Note also that the persistence of each regime is almost similar. This is confirmed by the estimated transition probabilities shown in Table C.4, which are fairly identical and imply an average duration of each regime of about eleven quarters.

\section{Economic implications}

Using the best-fit model, we provide quantitative sources of macroeconomic fluctuations since 1970. First, the role of all structural shocks in driving the macroeconomic fluctuations is examined through variance decompositions. We then provide evidence supporting the key role played by these shocks over the business cycles through historical decomposition. Finally, we present the impulse responses of variables to the most important shocks.

\subsection{Variance decompositions}

Tables C. 5 and C. 6 report the percentage of the variance of the error made (at the median) in forecasting each endogenous variable due to each specific structural shock across both regimes. The 90 percent error bands are indicated in brackets.

We can see directly from these tables that neutral technology shocks and MEI shocks are the dominant sources of business cycle fluctuations under both regimes. Overall, they account for about half of variations of output growth; namely, 23 - 30 percent by neutral 
shocks, and $24-29$ percent by MEl shocks under both regimes. A third of variations in consumption growth and hours are explained by these two types of shocks. Investment growth is accounted for predominantly by its own disturbances, i.e. MEl shocks (79- 85 percent). Besides, although the sizes of shock variances differ between both regimes, their relative importance remains relatively unchanged.

The contributions of the remaining shocks remain unimportant in explaining business cycle fluctuations, with two exceptions: 1) government shocks explain a sizable fraction of output (19-13 percent) and hours (21-16 percent) under both regimes; and 2) Preference shocks explain a large part of variations in consumption growth (31 - 25 percent).

Finally, IST shocks are unimportant. They only explain fluctuations of its own variable, i.e. the relative price of investment. This result corroborates with Justiniano, Primiceri, and Tambalotti (2011).

\subsection{Historical decompositions}

To illustrate the importance of shocks more clearly, Figure C.5 displays the historical decompositions of some observable variables in the estimated structural shocks. ${ }^{8}$ In particular, the panels of the first row display output growth (black line) together with the output growth series generated by the two most important shocks (green line): MEl shocks (first column), neutral technology shocks (second column) and the sum of the two latter shocks (third column). The panels of the second and the third rows repeat the same exercise for consumption growth and investment growth, respectively. There are several comments about this figure.

First, when looking at the first row (the output growth series), the two shocks that are the most relevant are the MEI shocks and the neutral technology shocks. Put together (first row, fourth column), they closely reproduce the historical output growth rate, including the output decline in the beginning of the Great Recession in 2008. Looking at U.S. business cycles, Justiniano, Primiceri, and Tambalotti (2011) also find that investmentspecific technological progress play a major role in explaining output variations. Our results corroborate with their conclusion and, therefore, we argue that the relative importance of this shock is robust across the two economies.

Second, only the neutral technology shocks seem to explain a notable part of the fluctuations of consumption growth. Strikingly, MEI shocks play only a minor historical role

\footnotetext{
${ }^{8}$ The full set of historical decompositions is available upon request.
} 
in explaining consumption volatility. None of these shocks explain the large decline of consumption growth during the recession of 1992-1993. Although not reported, this large decline results more from responses to its own disturbances than by responses to variables other than preference.

Third, the investment growth series generated by MEl shocks closely tracks the actual series. During the 1992-1993 recession, the decline in investment growth was mainly explained by shocks. In the most recent period, its role was also preponderant. In particular, since the 2000s, this shock follows nearly identically the expansion path of investment growth, and also of output growth, as previously mentioned. Given its importance, a closer inspection of this shock is examined in Section 6.

\subsection{Impulse responses}

The two previous sections provide some insight into how much the variance of variables is explained by each structural shock, but say nothing about how macroeconomic variables respond to these shocks. This is the objective of this section. First, we examine the estimated impulse responses of observable variables to a disturbance in $\mathrm{MEI}$, and technology, which represent the two most important sources of macroeconomic fluctuations. The thin black line represents the median and the the dotted line are the 90 percent probability intervals. As only the variance of shocks change over time, the dynamic effects remain the same across regimes. We therefore only report the impulse responses of one particular regime; namely the "high-volatility" regime.

Figure C.6 reports the impulse responses after a positive disturbance to neutral technology. This shock acts as a supply-side disturbance, pushing inflation and output in opposite directions. More specifically, output, consumption, and investment increase progressively, reach their maximum after ten quarters and remain high. Not surprisingly, inflation moves down immediately and then begins to recover steadily. The 90 percent error bands are remarkably tight, making the estimates very significant. Overall, the pattern of responses displayed in this figure is familiar from existing literature, with exception of the response of hours worked, which is still controversial. Its short-term decrease corroborates with the findings of Smets and Wouters (2007), Gali (1999), Francis and Ramey (2009), and Canova, Lopez-Salido, and Michelacci (2006), but contradicts Christiano, Eichenbaum, and Vigfusson (2004), Uhlig (2004), and Chang and Hong (2006).

Figure $C .7$ reports the impulse responses after a positive disturbance to the efficiency of investment. The efficiency of investment raises as the quantity or quality of investment 
goods increases. As a consequence, the allocation of resources shifts from consumption to investment, and thus current consumption decreases. Inflation, hours worked, and output move upward. As a result, the monetary authority responds by raising the nominal interest rate in order to mitigate the positive impact of the $\mathrm{MEI}$ shock on the real economy. Once again, the probability intervals confirm that the responses are well estimated. Note also that the transmission mechanisms of this shock to the economy is very similar to those reported in Justiniano, Primiceri, and Tambalotti (2011).

Although it has been estimated that the monetary policy shocks are not the dominant sources of business cycles in the euro area, it might be still relevant to display their transmission mechanism. Figure C.8 reports the impulse responses after a disturbance to monetary policy. The monetary shock raises the interest rate immediately and moves all other observable variables down. The precision of estimates can be evaluated by the constructed error bands. In each panel, error bands lie within the same region as the estimates at the median. This suggests that the dynamic is well preserved and that the pattern of each variable is robust. Since this shock has been largely investigated in the literature, we will not provide further explanations.

Note, however, how big the median responses of macroeconomic variables to a monetary policy shock. Actually, a one standard deviation monetary policy shock that moves the nominal interest rate by 7 basis points reduce output by -0.30 percent and inflation by -0.02 percent points. As previously observed, the importance of monetary shocks can be appreciated in Tables C. 5 and C. 6 that show a substantial contribution of monetary shocks to output growth and hours under both volatility-regime. Although these contributions are substantially larger than what those observed when this class of models is estimated on U.S. data, they corroborate with the existing literature for the euro area. For example, Peersman and Smets (2001) show that monetary policy shocks explain almost 40 percent of output variation at long horizons. Sahuc and Smets (2008) reveal that a 6 basis points increase in the nominal interest rate reduces output by -0.60 percent.

\section{Further inspection of marginal efficiency of investment}

In the model, the two dominant sources of euro area business cycles are the neutral technological shocks and MEl shocks. Whereas the former is standard in the literature, the latter remains relatively new and, therefore, little attention has been given to this shock. In this section, we attempt to provide a structural interpretation of this.

As highlighted in Justiniano, Primiceri, and Tambalotti (2011), one possible interpretation 
may be found in financial conditions. These authors argue that an important part of the process by which investment goods are transformed into capital goods, through MEI shocks, is attributed to the financial cost of borrowing. Suppose that capital producers must contract a loan to buy investment goods. In this case, the ability of households to raise funds is an important determinant of the creation of productive capital in the economy. Indeed, a reduction in the cost to borrowers causes inevitably a decrease in the relative cost of investment and, therefore, an increase in the efficiency with which investment goods are transformed into physical capital. Put differently, an accumulation of negative shocks to $\mathrm{MEI}, \mu_{t}$, decreases the amount of effective capital installed ${ }^{9}$, indicating that $\mu_{t}$ is a good proxy for the cost of market funding for households.

We can go further in the relationships between $\mu_{t}$ and financial conditions by looking at the financial accelerator model of Carlstrom and Fuerst (1997). In this setting, when entrepreneurs need to borrow from external lenders (households), there are endogenous monitoring costs associated with enforcing contracts causing the destruction of some investment goods and thus reducing the process of capital formation

$$
\bar{K}_{t}=(1-\delta) \bar{K}_{t-1}+\left(1-\Psi_{t}\right) I_{t}
$$

where $\Psi_{t}$ represents the total amount of new capital destroyed by monitoring.

The mechanism in Carlstrom and Fuerst (1997) is straightforward. When the economy is growing, firms have stronger balance sheets. As a consequence, they appear to be less risky, so lenders reduce their monitoring costs and the external finance premium, which increases new productive capital and further contributes to economic growth. Our MEI shock act exactly in the same way, in the sense that it affects the aggregate amount of effective capital in the economy.

To prove our interpretation, we consider the question of how good is the correlation between MEl shocks and the external finance premium. To do so, we use the constructed credit spread by Gilchrist and Mojon (2014) as indicator of credit cost and thus as proxy for the external finance premium. They construct their corporate bond spread by using the market price of bonds issued by euro area non-financial corporations. The difference between each security and the German Bund interest rate of similar duration represents the credit spread. The average is obtained by weighting each credit spread by their corresponding volumes. We choose such a spread because it has been shown it is a good

\footnotetext{
${ }^{9}$ Our MEl shock can be interpreted as a shock to the quality of capital given that this shock affects the value of capital and, therefore, the return on capital. In this case, our MEl shock can be related to the capital quality shock in Gertler and Kiyotaki (2010).
} 
predictor of economic activity and, more generally, outperforms other measures.

Figure C.9 displays the historical path of the MEl series at the median (with the 90 percent probability intervals) in tandem with the non-financial credit spread from 1999:Q1 to 2012:Q1. Since the credit spread series is only available only from 1999 on, we do not include the preceding period in the graph. Clearly, MEl time series is remarkably well correlated with the constructed non-financial corporations credit spread. In particular, the correlation at median is -0.70 indicating that the higher is financial stress, the lower is the MEI shock. Therefore, these empirical evidence highlight the major role of financial system in economic activity of the euro area.

\section{Robustness: The role of monetary policy changes}

The analytical framework of this paper may be potentially problematic as it may not identify the correct source of time variation. Suppose that the creation of European Monetary Union has led to important changes in the conduct of monetary policy. For example, Avouyi-Dovi and Sahuc (2013) find that, by estimating a DSGE model with euro area data using two distinct subsamples, the ECB has conducted a more aggressive policy reaction to inflation since 1999. By conducting an improved monetary policy, the monetary authority moderates the real effects of demand fluctuations and thus decreases the variability of main macroeconomic aggregates.

Suppose further that the model kept the monetary policy parameters invariant and allowed only shock variances to drift over time, as in our modeling framework. Since the monetary policy parameters are held constant, the estimated model would fail to detect any drift in policy. On the other hand, the model makes allowances for changes in shock variances over time, and these changes may be a primary source of the volatility of euro area macroeconomic variables over the past decades. Since this time-varying volatility model is a serious candidate for the explanation of changes in volatility, shock variances are likely to change in order to compensate for the absence of monetary policy regimes.

The objective of this section is to provide evidence that changes in policy parameters are not the primary source of changes in macroeconomic volatility of the euro area, especially for the decline of major macroeconomic time series in 1993. Indeed, our reduced-form analysis in Section 2, reveals that a break in 1993 describes the euro area data well, especially for output growth, wages growth and interest rate.

Our robustness check appears legitimate, especially as the break in the data coincides with one of several steps of monetary integration. Indeed, from the creation of the European 
Monetary System in March 1979 to the introduction of the single currency in 1999, right through to the establishment of the European Monetary Institute (EMI) in 1994, several steps have been cleared with the aim of reducing inflation and greater economic stability. All of these suggest that the monetary policy in the euro area has been better in the early 1990 s and it has been importantly contributed to the decline of macroeconomic volatility.

In this section, we estimate our two-state variance DSGE model with a deterministic single break in monetary policy parameters in $1993 .{ }^{10}$ For obvious reasons, the pre-1993 period is called the pre-EMU period, and the post-1993 period is called the post-EMU period. We then compare the fit of this alternative model with our best-fit model and also conduct several counterfactual exercises in the equation describing monetary policy to compare output and inflation observed in the data with those predicted by the model.

\subsection{Results from the single break model}

The theoretical DSGE model used in this section is similar to the one employed previously, as well as the eight observation variables. ${ }^{11}$ Moreover, the prior distributions are the same as those equipped in the time-varying volatility DSGE model. In particular, the prior variance distribution for the policy parameter which determines the nominal interest rate response to inflation (with the mean 1.70 and standard deviation 0.30 ) remains unchanged and is large enough to explore a large part of the parameter space. We once again truncate this prior at the boundary of the determinacy region.

Posterior distributions (medians with a 90 percent probability interval) of the structural parameters and shock processes under each subsample are reported in Tables C.7 and C.8. The estimated response of policy rate to inflation movements was less aggressive in the pre-euro period than it was in the the post-euro period. The estimate for $\psi_{\alpha}$, the nominal interest rate response to inflation, is 1.55 with the probability interval $[1.22 ; 1.89]$ in the first subsample, while its estimates are about 1.89 with the probability interval $[1.53 ; 2.24]$ in the post-1993. These policy-parameter changes do not appear significant in the sense that the 90 percent error bands overlap. Moreover, these estimates reveal that the behavior of monetary authority between the two subsamples are noticeably but not

\footnotetext{
${ }^{10}$ Although a break in 1993 seems to describe well the following time series: output growth, wages growth and interest rate; the 1999 year seems to be an appropriate date for consumption growth and investment growth. For this reason, we have also estimated our model with a single break in 1999 and the results remain unchanged.

${ }^{11}$ To analyze the pre- and post- EMU periods, Avouyi-Dovi and Sahuc (2013) add an eighth observable series in their DSGE model; namely, a monetary aggregate. We do not include such a variable in our modeling framework.
} 
dramatically different. Consequently, this is different from Avouyi-Dovi and Sahuc (2013), who find more pronounced differences in the policy behavior between both samples.

Looking back at the table C.2, which also displays the log value of MDD for this singlebreak model, $\mathfrak{M}_{2 v+M p}$. it is apparent to see that allowing a single break in parameters of monetary policy does not improve the fit with respect to our best-fit model. Indeed, the former still delivers the best-fit with a log-value difference of 23.56, relative to $\mathfrak{M}_{2 v+M p}$, meaning that there were not a drastic change in the way of ECB has conducted monetary policy over time.

\subsection{Counterfactual analyses}

The previous results have shown notable, but not drastic, differences in the way the interest rate responds to inflation before and after 1993. Although not important, these differences might still explain the large decline in volatility.

The counterfactual simulation that we consider is straightforward. First, a set of parameter draws is generated from the posterior distributions using the Gibbs-sampling procedure mentioned in Appendix B. Second, for each 1,000th draw, we replace the estimated coefficients describing the monetary policy of the first subsample by those estimated in the second subsample and we generate 1,000 samples with the same length as the data. Such a counterfactual responds directly to our question: what would the volatility of output and inflation had been if monetary policy from the model of the first sub-period (characterized by the higher macroeconomic volatility) had been transplanted into the model for the second sub-period (characterized by the lower macroeconomic volatility)?

These counterfactual standard deviations for output and inflation, as well as the estimated standard deviations implied by the right model, are reported in Table C.9. Clearly, changing the monetary policy equation was unimportant in explaining the decline in cyclical fluctuations in output and inflation. Indeed, by comparing the first column (1) with the third column (3), the standard deviations of output and inflation remain stable and far higher than of the variability implied by the second subsample model [column (2)].

The fact that we found that monetary policy has played an unimportant role in explaining the decline of macroeconomic variability since the beginning of 1993 provides additional support for the main finding of this paper; namely that the decline of the size of structural shocks plays an important role in explaining the decline in macroeconomic volatility of the euro area. 


\section{Conclusion}

The first objective in this paper was to document the large decline in euro area business cycles from the early 1990s to the Great Recession in 2008. The second objective was to provide the sources of these changes. From the various models we estimated and the several economic implications we explored, we reach the following conclusions:

- There is evidence of synchronized changes in shock variances over time. The highvolatility regime has predominantly prevailed in the 1970s, sporadically in the 1980s and 1990s, and during the Great Recession.

- The relative importance of shocks remains unchanged across the two regimes. Neutral technology shocks and MEI (i.e., exogenous variation in the efficiency with which the final good can be transformed into physical capital) shocks are the dominant sources of business cycle fluctuations.

- There is evidence that the MEl shock is a good proxy for the premium for external finance. 


\section{References}

Altig, D., L. Christiano, M. Eichenbaum, and J. Linde (2011): "Firm-specific Capital, Nominal Rigidities, and the Business Cycle," Review of Economic Dynamics, 14(2), 225-247.

An, S., and F. Schorfheide (2007): "Bayesian Analysis of DSGE Models," Econometric Review, 26(2-4), 113-172.

Angeloni, I., A. Kashyap, and B. Mojon (2003): Monetary Transmission in the Euro Area.

Avouyi-Dovi, S., and J.-G. Sahuc (2013): "On the Sources of Macroeconomic Stability in the Euro Area," Working paper.

Bernanke, B. S., and I. Mihov (1998): "Measuring Monetary Policy," Quarterly Journal of Economics, 113(3), 869-902.

Bianchi, F. (2013): "Regimes Switches, Agents' Beliefs, and Post-World War II U.S. Macroeconomic Dynamics," Review of Economic Studies, 80(2), 463-490.

Bianchi, F., and C. Ilut (2014): "Monetary/Fiscal Policy Mix and Agents' Beliefs," Working Paper.

Calvo, G. A. (1983): "Staggered Prices in a Utility-maximizing Framework," Journal of Monetary Economics, 12(3), 383-98.

Canova, F., L. Gambetti, and E. Pappa (2008): "The Structural Dynamics of Output Growth and Inflation: Some International Evidence," Economic Journal, 117, C167-C191.

Canova, F., D. Lopez-Salido, and C. Michelacci (2006): "On the Robust Effects of Technology on Hours Worked and Output," Mimeo, Universitat Pompeu Fabra.

Carlstrom, C. T., and T. S. Fuerst (1997): "Agency Costs, Net Worth, and Business Fluctuations: A Computable General Equilibrium Analys," American Economic Review, 87(5), 893-910.

Cecioni, M., and S. Neri (2011): “The Monetary Transmission Mechanism in the Euro Area: Has It Changed and Why?," Working Paper, Banca d'Italia.

Chang, Y., and J. H. Hong (2006): "Do Technological Improvements in the Manufacturing Sector Raise or Lower Employment?," American Economic Review, 96(1), 352-368.

Christiano, L., M. Eichenbaum, and R. Vigfusson (2004): "What Happens After a Technology Shock?," Mimeo, Northwestern University.

Christiano, L. J., M. Eichenbaum, and C. L. Evans (2005): "Nominal Rigidities and the Dynamic Effects of a Shock to Monetary Policy," Journal of Political Economy, 113(1), 1-45. 
Clarida, R., J. Gali, and M. Gertler (1998): "Monetary Policy Rules in Practice: Some International Evidence," European Economic Review, 42, 1033-1067.

Clarida, R., J. Gali, and M. Gertler (2000): "Monetary Policy Rules and Macroeconomic Stability: Evidence and Some Theory," The Quarterly Journal of Economics, (2), 147-180.

Cogley, T., and T. J. Sargent (2005): "Drift and Volatilities: Monetary Policies and Outcomes in the Post-WWII U.S.," Review of Economic Dynamics, 8, 262-302.

Davig, T., and T. Doh (2013): "Monetary Policy Regime Shifts and Inflation Persistence," Review of Economics and Statistics, forthcoming.

Erceg, C. J., D. W. Henderson, and A. T. Levin (2000): "Optimal Monetary Policy with Staggered Wage and Price Contracts," Journal of Monetary Economics, 46(2), 281-313.

Fagan, G., J. Henry, and R. Mestre (2005): "An Area-wide Model for the Euro Area," Economic Modelling, 22, 39-59.

Fisher, J. D. M. (2006): "The Dynamic Effects of Neutral and Investment-Specific Technology Shocks," Journal of Political Economy, 114(3), 413-451.

Francis, N., and V. A. Ramey (2009): "Measures of Hours Per Capita and their Implications for the Technology-Hours Debate," Journal of Money, Credit, and Banking, 41(6), 1071-1097.

Fruhwirth-Schnatter, S. (2004): "Estimating Marginal Likelihoods for Mixture and Markov Switching Models using Bridge Sampling Techniques," Econometrics Journal, 7(1), 143-167.

Gali, J. (1999): "Technology, Employment, and the Business Cycle: Do Technology Shocks Explain Aggregate Fluctuations?," American Economic Review, 89(1), 249-271.

Gertler, M., and N. Kiyotaki (2010): "Financial Intermediation and Credit Policy in Business Cycle Analysis," Handbook of Monetary Economics, 3, 547-599.

Geweke, J. (1999): "Using Simulation Methods for Bayesian Econometric Models: Inference, Development, and Communication," Econometric Review, 18(1), 1-73.

Gilchrist, S., and B. Mojon (2014): "Credit Risk in the Euro area," Banque de France Working paper.

Hamilton, J. D. (1989): "A New Approach to the Economic Analysis of Nonstationary Time Series and the Business Cycle," Econometrica, 57, 357-384.

Hamilton, J. D., D. F. Waggoner, and T. Zha (2007): "Normalization in Econometrics," Econometric Reviews, 26, 221-252. 
Justiniano, A., and G. E. Primiceri (2008): "The Time-varying Volatility of Macroeconomic Fluctuations," American Economic Review, 98(3), 601-641.

Justiniano, A., G. E. Primiceri, and A. Tambalotti (2011): "Investment Shocks and the Relative Price of Investment," Review of Economic Dynamics, 14(1), 101-121.

Kim, C.-J. (1994): "Dynamic Linear Models with Markov-switching," Journal of Econometrics, 60, $1-22$.

Kim, C.-J., and C. R. Nelson (1999): State-space Models with Regime Switching, MIT Press Books. The MIT Press.

Lhuissier, S., and M. Zabelina (2015): "On the Stability of Calvo-Style Price-Setting Behavior," Journal of Economic Dynamics and Control, 57, 77-95.

Liu, Z., D. F. Waggoner, and T. Zha (2011): "Sources of Macroeconomic Fluctuations: A Regimeswitching DSGE Approach," Quantitative Economics, 2(2), 251-301.

Lubik, T., and F. Schorfheide (2004): "Testing for Indeterminacy: An Application to U.S. Monetary Policy," American Economic Review, 94(1), 190-219.

Meng, X., and W. H. Wong (1996): "Simulating Ratios of Normalizing Constants Via a Simple Identity: A Theoretical Exploration," Statistica Sinica, (6), 831-860.

Ohanian, L. E., and A. Raffo (2012): "Aggregate Hours Worked in OECD Countries: New Measurement and Implications for Business Cycles," Journal of Monetary Economics, 59(1), 40-56.

Peersman, G., and F. Smets (2001): "The Monetary Transmission Mechanism in the Euro Area: More Evidence from VAR Analysis," Working Paper.

Primiceri, G. E. (2005): "Time-varying Structural Vector Autoregressions and Monetary Policy," Review of Economic Studies, 72, 821-852.

Sahuc, J.-G., and F. Smets (2008): "Differences in Interest Rate Policy at the ECB and the Fed: An Investigation with a Medium-scale DSGE Model," Journal of Money, Credit, and Banking, 40(2-3), 505-521.

Sims, C. A., D. F. Waggoner, and T. Zha (2008): "Methods for Inference in Large Multipleequation Markov-switching Models," Journal of Econometrics, 146, 255-274.

Sims, C. A., and T. Zha (2006): "Were There Regime Switches in U.S. Monetary Policy?," American Economic Review, 96(1), 54-81.

Smets, F. R., and R. Wouters (2007): "Shocks and Frictions in U.S. Business Cycles: A Bayesian DSGE Approach," American Economic Review, 97(3), 586-606. 
Uhlig, H. (2004): "Do Technology Shocks Lead to a Fall in Total Hours Worked," Journal of the European Economic Association, 2(2-3), 361-371. 


\section{Appendix}

\section{A. Linear rational expectations model}

In what follows, we provide the stationary equilibrium of the model, the linearized equilibrium dynamics and the model solution.

\section{A.1. Stationary equilibrium}

The level of neutral and investment-specific technology have a unit root. The composite trend is then $A_{t} \Upsilon_{t}^{\frac{\alpha}{1-\alpha}}$ with the following steady state growth rate

$$
\gamma^{*}=\gamma^{z}+\frac{\alpha}{1-\alpha} \gamma^{\mu}
$$

Several variables are then transformed to induce stationarity as follows:

$$
\begin{gathered}
\tilde{Y}_{t}=\frac{Y_{t}}{A_{t} \Upsilon_{t}^{\frac{\alpha}{1-\alpha}}}, \quad G \tilde{D} P_{t}=\frac{G D P_{t}}{A_{t} \Upsilon_{t}^{\frac{\alpha}{1-\alpha}}}, \quad \tilde{K}_{t}=\frac{K_{t}}{A_{t} \Upsilon_{t}^{\frac{\alpha}{1-\alpha}}}, \\
\tilde{C}_{t}=\frac{C_{t}}{A_{t} \Upsilon_{t}^{\frac{\alpha}{1-\alpha}}}, \quad \tilde{l}_{t}=\frac{I_{t}}{A_{t} \Upsilon_{t}^{\frac{\alpha}{1-\alpha}}}, \quad \tilde{W}_{t}=\frac{W_{t}}{A_{t} \Upsilon_{t}^{\frac{\alpha}{1-\alpha}} P_{t}} .
\end{gathered}
$$

The marginal utility of nominal income, $\Lambda_{t} P_{t}$, and the multiplier on the capital accumulation equation (i.e., the shadow value of installed physical capital) $\Phi_{t}$, are transformed to induce stationarity as well

$$
\tilde{\Lambda}_{t}=\Lambda_{t} A_{t} \Upsilon_{t}^{\frac{\alpha}{1-\alpha}} P_{t}, \quad \text { and } \quad \tilde{\Phi}_{t}=\Phi_{t} A_{t} \Upsilon_{t}^{\frac{\alpha}{1-\alpha}}
$$

\section{A.2. Linearized equilibrium dynamics}

Once the model is rewritten in a stationary form, the steady state of the model is computed and then log-linearized around its non-stochastic steady state. The log-deviations of the stationary variable $X_{t}$ from its steady state value is denoted $\hat{X}_{t}$ and defined as $\hat{X}_{t}=$ $\ln X_{t}-\ln X$.

A log-linear approximation of the solution to the firms' price-setting problem is expressed as follows:

$$
\tilde{\pi}_{t}=\frac{\beta}{1+\iota_{p} \beta} \mathrm{E}_{t} \tilde{\pi}_{t+1}+\frac{\iota_{p}}{1+\iota_{p} \beta} \tilde{\pi}_{t-1}+\frac{\left(1-\xi_{p} \beta\right)\left(1-\xi_{p}\right)}{\xi_{p}\left(1+\iota_{p} \beta\right)} \tilde{s}_{t}+\frac{\left(1-\xi_{p} \beta\right)\left(1-\xi_{p}\right)}{\xi_{p}\left(1+\iota_{p} \beta\right)} \tilde{\lambda}_{p, t} .
$$

This is the New-Keynesian Phillips Curve (NKPC) equation in which the current inflation depends on the real marginal cost $\left(\tilde{s}_{t}\right)$ the expected future inflation, and the lagged inflation. 
A log-linear approximation of the optimal wage-setting decision rule implies that

$$
\begin{aligned}
\tilde{\bar{w}}_{t}= & \xi_{w} \beta \mathrm{E}_{t}\left(\tilde{\bar{w}}_{t+1}+\tilde{\pi}_{t+1}\right)+\frac{1-\xi_{w} \beta}{1+\nu\left(1+\frac{1}{\lambda_{w}}\right)} \tilde{x}_{t}-\iota_{w} \xi_{w} \beta \tilde{\pi}_{t} \\
& +\xi_{w} \beta\left[\left(\rho_{z}-\iota_{w}\right) \tilde{z}_{t}+\left(\rho_{\mu}-\iota_{w}\right) \frac{\alpha}{1-\alpha} \tilde{\mu}_{t}\right]
\end{aligned}
$$

where $\tilde{w}_{t}$ denotes the log-deviations of the real wage. This is the so-called wage Phillips curve equation.

The real wages indexation

$$
\begin{aligned}
\tilde{w}_{t}=\left(1-\xi_{w}\right) \tilde{\bar{w}}_{t}+\xi_{w} \tilde{w}_{t-1} & -\xi_{w}\left(\tilde{\pi}_{t}+\tilde{z}_{t}+\frac{\alpha}{1-\alpha} \tilde{\mu}_{t}\right) \\
& +\iota_{w} \xi_{w}\left(\tilde{\pi}_{t-1}+\tilde{z}_{t-1}+\frac{\alpha}{1-\alpha} \tilde{\mu}_{t-1}\right)
\end{aligned}
$$

Linearizing the marginal utility of labor implies that

$$
\begin{aligned}
\tilde{x}_{t}= & \frac{1+\nu\left(1+\frac{1}{\lambda_{w}}\right)}{1-\xi_{w} \beta}(1+\beta) \frac{\xi_{w}}{1-\xi_{w}} \tilde{\psi}_{t}+\frac{e^{\gamma^{*}} h+e^{\gamma^{* 2}}+\beta h^{2}}{\left(1-\rho_{b}\right)\left(e^{\gamma^{*}}-h \beta \rho_{b}\right)\left(e^{\gamma^{*}}-h\right)} \tilde{b}_{t} \\
& +\nu \tilde{L}_{t}-\tilde{\lambda}_{t}+\nu\left(1+\frac{1}{\lambda_{w}}\right) \tilde{w}_{t}
\end{aligned}
$$

Linearizing the marginal utility of income implies that

$$
\begin{aligned}
\tilde{\lambda}_{t}= & \frac{h \beta e^{\gamma^{*}}}{\left(e^{\gamma^{*}}-h \beta\right)\left(e^{\gamma^{*}}-h\right)} E_{t} \tilde{c}_{t+1}-\frac{e^{\gamma^{* 2}}+h^{2} \beta}{\left(e^{\gamma^{*}}-h \beta\right)\left(e^{\gamma^{*}}-h\right)} \tilde{c}_{t}+\frac{h e^{\gamma^{*}}}{\left(e^{\gamma^{*}}-h \beta\right)\left(e^{\gamma^{*}}-h\right)} \tilde{c}_{t-1} \\
& +\frac{h \beta e^{\gamma^{*}} \rho_{z}-h e^{\gamma^{*}}}{\left(e^{\gamma^{*}}-h \beta\right)\left(e^{\gamma^{*}}-h\right)} \tilde{z}_{t}+\left(\frac{h \beta e^{\gamma^{*}} \rho_{\mu}-h e^{\gamma^{*}}}{\left(e^{\gamma^{*}}-h \beta\right)\left(e^{\gamma^{*}}-h\right)}\right) \frac{\alpha}{1-\alpha} \tilde{\mu}_{t} \\
& +\frac{e^{\gamma^{*}}\left(e^{\gamma^{*}}+h\right)+\beta h^{2}}{\left(1-\rho_{b}\right)\left(e^{\gamma^{*}}-h\right)\left(e^{\gamma^{*}}-h \beta\right)} \tilde{b}_{t}
\end{aligned}
$$

where $\tilde{\lambda}_{t}=\tilde{R}_{t}+\mathrm{E}_{t}\left(\lambda_{t+1}-\tilde{z}_{t+1}-\rho_{\mu} \frac{\alpha}{1-\alpha} \tilde{\mu}_{t+1}-\tilde{\pi}_{t+1}\right)$ is the Euler equation. 
The other log-linearized equilibrium conditions are as follows:

$$
\begin{aligned}
& \tilde{y}_{t}=\frac{y+F}{y}\left[\alpha \tilde{k}_{t}+(1-\alpha) \tilde{L}_{t}\right] \text {, } \\
& \tilde{\rho}_{t}=\tilde{w}_{t}+\tilde{L}_{t}-\tilde{k}_{t}, \\
& \tilde{s}_{t}=\alpha \tilde{\rho}_{t}+(1-\alpha) \tilde{w}_{t}, \\
& \tilde{\rho}_{t}=\chi \tilde{u}_{t}, \\
& \tilde{\phi}_{t}=(1-\delta) \beta e^{-\left(\gamma^{*}+\gamma^{\mu}\right)} \mathrm{E}_{t} \tilde{\phi}_{t+1}-\rho_{z} \tilde{z}_{t}+\left(1-(1-\delta) \beta e^{-\left(\gamma^{*}+\gamma^{\mu}\right)}\right) \mathrm{E}_{t}\left[\tilde{\lambda}_{t+1}+\tilde{\rho}_{t+1}\right] \\
& -\rho_{\mu}\left(\frac{\alpha}{(1-\alpha)}+1\right) \tilde{\mu}_{t} \\
& \tilde{\lambda_{t}}=\tilde{\phi}_{t}+\tilde{\mu}_{t}-e^{\left(\gamma^{*}+\gamma^{\mu}\right)^{2}} S^{\prime \prime}\left[\tilde{i}-\tilde{i}_{t-1}+\tilde{z}_{t}+\left(\frac{\alpha}{(1-\alpha)}+1\right) \tilde{\mu}_{t}\right] \\
& +\beta e^{\left(\gamma^{*}+\gamma^{\mu}\right)^{2}} S^{\prime \prime} E_{t}\left[\tilde{i}_{t+1}-\tilde{i}_{t}+\tilde{z}_{t+1}+\left(\frac{\alpha}{(1-\alpha)}+1\right) \tilde{\mu}_{t+1}\right] \\
& \tilde{k}_{t}=\tilde{u}_{t}+\widehat{\bar{k}}_{t-1}-\tilde{z}_{t}-\left(\frac{\alpha}{1-\alpha}+1\right) \tilde{\mu}_{t}, \\
& \widehat{\bar{k}}_{t}=(1-\delta) e^{-\gamma^{*}-\gamma^{\mu}}\left[\widehat{\bar{k}}_{t}-\tilde{z}_{t}-\left(\frac{\alpha}{1-\alpha}+1\right) \tilde{\mu}_{t}\right]+\left(1-(1-\delta) e^{-\gamma^{*}-\gamma^{\mu}}\right)\left(\tilde{v}_{t}+\tilde{i}_{t}\right) \text {, } \\
& g \tilde{d} p_{t}=\tilde{y}_{t}-\frac{\rho k}{y} \tilde{u}_{t} \\
& \frac{1}{g} \tilde{y}_{t}=\frac{1}{g} \tilde{g}_{t}+\frac{c}{y} \tilde{c}_{t}+\frac{i}{y} \tilde{i}_{t}+\frac{\rho k}{y} \tilde{u}_{t}
\end{aligned}
$$

where (53) is the linearized production function for the intermediate good producer; (54) is the linearized capital labor ratio with $\tilde{\rho}_{t}$ as the real rental rate of capital $\left(\rho_{t}=r_{t}^{k} / P\right)$; (55) is the linearized marginal cost; (56) is the linearized capacity utilization decision equation; (57) is the linearized optimal choice of physical capital stock; (58) is the linearized optimal choice of investment; (59) is the linearized definition of capital input; (60) is the linearized law of motion for the capital stock; (61) is the linearized definition of GDP; and (62) is the linearized resource constraint.

Finally, the monetary policy rule is given by:

$$
\begin{aligned}
\tilde{R}_{t}= & \rho_{R} \tilde{R}_{t-1}+\left(1-\rho_{R}\right)\left[\psi_{\pi} \tilde{\pi}_{t}+\phi_{X}\left(g \tilde{d} p_{t}-g \tilde{d} p_{t}^{*}\right)\right] \\
& +\phi_{d x}\left[\left(g \tilde{d} p_{t}-g \tilde{d} p_{t-1}\right)-\left(g \tilde{d} p_{t}^{*}-g \tilde{d} p_{t-1}^{*}\right)\right]+\tilde{\eta}_{m p, t} .
\end{aligned}
$$

The size of the system to solve rises to 62 when taking into account shock processes, the variables characterizing the flexible economy, and the following five lagged variables: output, consumption, investment, real wages, and hours worked. These lagged variables are needed so that observable variables (most of them are in the growth rate) are a function 
of the state vector. Once linearized, we directly employ a standard technique to solve the DSGE model since the model solution is unaffected by time variation in shock variances [Justiniano and Primiceri (2008) and Liu, Waggoner, and Zha (2011)]. We employ the GENSYS program proposed by Sims (2002).

\section{B. The Methodology}

A Bayesian approach is used to estimate the parameters of MS-DSGE models. Briefly, we present the employed general empirical strategy. Once solved, the model solution can be compacted to form the transition equation as follows:

$$
f_{t}=G f_{t-1}+C\left(s_{t}\right) \epsilon_{t},
$$

where $f_{t}$ contains state variables, $\epsilon_{t}=\left[\varepsilon_{p, t}, \varepsilon_{b, t}, \varepsilon_{z, t}, \varepsilon_{m p, t}, \varepsilon_{w, t}, \varepsilon_{v, t}, \varepsilon_{g, t}, \varepsilon_{\mu, t}\right]$ is a vector containing all structural shocks, and $C\left(s_{t}\right)$ is a matrix function of all standard deviations of structural shocks $\sigma_{p, t}\left(s_{t}\right), \sigma_{b, t}\left(s_{t}\right), \sigma_{v, t}\left(s_{t}\right), \sigma_{z, t}\left(s_{t}\right), \sigma_{m p, t}\left(s_{t}\right), \sigma_{w, t}\left(s_{t}\right), \sigma_{g, t}\left(s_{t}\right)$, and $\sigma_{\mu, t}\left(s_{t}\right)$. For $1 \leq i, j \leq h$, the discrete and unobserved variable $s_{t}$ is an exogenous firstorder Markov process with the transition probabilities

$$
q_{i, j}=\operatorname{Pr}\left(s_{t}=i \mid s_{t-1}=j\right)
$$

where $h$ is the total number of regimes.

We employ quarterly euro area time series from 1970.Q2-2012.Q1 on eight aggregate variables: real per capita GDP ( $\left.Y_{t}^{\text {Data }}\right)$; real per capita consumption $\left(C_{t}^{\text {Data }}\right)$; real per capita investment $\left(I_{t}^{\text {Data }}\right)$; real wage $\left(W_{t}^{\text {Data }}\right)$; per capita hours $\left(L_{t}^{\text {Data }}\right)$; the quarterly GDPdeflator inflation rate $\left(\pi_{t}^{\text {Data }}\right)$; the short-term (3-months) nominal interest rate $\left(R_{t}^{\text {Data }}\right)$; and the relative price of investment $\left(\mathrm{P}_{/ t}^{\mathrm{Data}}\right)$. To be in line with the model, we construct real series by dividing the nominal series by population and the chain-weighted deflator for consumption. We stack this data in the following vector of observable variables:

$$
y_{t}=\left[\Delta \ln Y_{t}^{\text {Data }}, \triangle \ln C_{t}^{\text {Data }},\left.\Delta \ln \right|_{t} ^{\text {Data }}, \pi_{t}^{\text {Data }}, R_{t}^{\text {Data }}, \Delta \ln W_{t}^{\text {Data }}, \Delta L_{t}^{\text {Data }}, \Delta \ln P_{/ t}^{\text {Data }}\right]^{\prime},
$$

where $\triangle \ln X_{t}^{\text {Data }}$ denotes the first difference of the logarithm of $X_{t}^{\text {Data }}$. Note that, following Avouyi-Dovi and Sahuc (2013), we use a new series of quarterly hours worked for the euro area constructed by Ohanian and Raffo (2012), instead of an employment series. In turn, our specification does not require an ad-hoc employment adjustment equation that translates hours worked into the employment series as it is commonly used in the euro area literature. 
The measurement equations relate the evolution of observed time series $y_{t}$ to unobserved variables $f_{t}$ :

$$
y_{t}=a+H f_{t}
$$

where

$$
a=\left[100 \gamma^{*}, 100 \gamma^{*}, 100 \gamma^{*}, 100(\pi-1), 100(\pi-1)+R^{s s}, 100 \gamma^{*}, 100 \gamma^{v}\right]^{\prime}
$$

It follows, from (64) and (67), that only the transition equations depend on the regime $s_{t}$. The standard Kalman filter [An and Schorfheide (2007)] is irrelevant to evaluate the likelihood of the model due to the quasi non-linearity of the model. We then exploit the Kim and Nelson (1999)'s filter to construct the likelihood distribution. The next section provides a detailed description of this filter.

\section{B.1. The posterior distribution}

To form the posterior density, $p\left(\theta, \Xi, Q, F_{T}, S_{T} \mid Y_{T}\right)$, we combine the overall likelihood function $p\left(Y_{T} \mid \theta, \Xi, Q, F_{T}, S_{T}\right)$ with the prior $p\left(\theta, \Xi, Q, F_{T}, S_{T}\right)$ :

$$
p\left(\theta, \equiv, Q, F_{T}, S_{T} \mid Y_{T}\right) \propto p\left(Y_{T} \mid \theta, \equiv, Q, F_{T}\right) p\left(\theta, \equiv, Q, F_{T}, S_{T}\right),
$$

where $\theta$ contains structural parameters, $\equiv$ are shock variances, $Q=\left(q_{i, j}\right)$ are the parameters from the transition matrix, $F_{t}=\left\{f_{1}, \cdots, f_{t}\right\}$ is the historical path of DSGE state vector, and $S_{t}=\left\{s_{1}, \cdots, s_{t}\right\}$ is the historical path of Markov-switching states, $Y_{t}=\left\{y_{1}, \cdots, y_{t}\right\}$ represents the entire sequence of the observable variables, and $T$ is the sample size.

The likelihood, $p\left(Y_{T} \mid \theta, \equiv, Q\right)$ The evaluation of the overall likelihood function is obtained using the Kim and Nelson (1999) filter, which is a combination of the Kalman filter and the Hamilton (1989) filter. Let $p\left(y_{t} \mid s_{t}, s_{t-1}, Y_{t-1}, \theta, Q, \Xi\right)$ be the conditional likelihood function, given $s_{t}, s_{t-1}$. By integrating $s_{t}$ and $s_{t-1}$ out, the likelihood function at date $t$ is as follows:

$$
p\left(y_{t} \mid Y_{t-1}, \theta, \Xi, Q\right)=\sum_{s_{t}} \sum_{s_{t-1}} p\left(y_{t} \mid s_{t}, s_{t-1}, Y_{t-1}, \theta, \Xi, Q\right) \operatorname{Pr}\left[s_{t}, s_{t-1} \mid Y_{t-1}, Q, \theta, \equiv\right]
$$

with

$$
\operatorname{Pr}\left[s_{t}, s_{t-1} \mid Y_{t-1}, Q, \theta, \equiv\right]=\operatorname{Pr}\left[s_{t} \mid s_{t-1}\right] \operatorname{Pr}\left[s_{t-1} \mid Y_{t-1}, Q, \theta, \equiv\right]
$$


where $\operatorname{Pr}\left[s_{t} \mid s_{t-1}\right]$ is the transition probability previously described. We then update the joint probability term in the following way:

$$
\begin{aligned}
\operatorname{Pr}\left[s_{t}, s_{t-1} \mid Y_{t}, \theta, Q, \Xi\right] & =\frac{p\left(y_{t}, s_{t}, s_{t-1} \mid Y_{t-1}, \theta, Q, \Xi\right)}{p\left(y_{t} \mid Y_{t-1}, Q, \theta, \Xi\right)} \\
& =\frac{p\left(y_{t} \mid s_{t}, s_{t-1}, Y_{t-1}, \theta, Q, \Xi\right) \cdot \operatorname{Pr}\left(s_{t}, s_{t-1} \mid \psi_{t-1}\right)}{p\left(y_{t} \mid Y_{t-1}, Q, \theta, \Xi\right)},
\end{aligned}
$$

and finally we obtain the probability term given the information at date $t$

$$
\operatorname{Pr}\left[s_{t} \mid Y_{t}, Q, \theta, \equiv\right]=\sum_{s_{t-1}} \operatorname{Pr}\left[s_{t}, s_{t-1} \mid Y_{t}, Q, \theta, \equiv\right]
$$

The overall likelihood is

$$
p\left(Y_{T} \mid \theta, \Xi, Q\right)=\prod_{t=1}^{T} p\left(y_{t} \mid Y_{t-1}, Q, \theta, \Xi\right) .
$$

Once the parameters of the model are estimated, we follow Kim (1994) and Kim and Nelson (1999) and make inference on $s_{T}$, the smoothed probabilities, in the following way:

$$
\operatorname{Pr}\left[s_{t}=j \mid Y_{T}, Q, \theta, \equiv\right]=\sum_{i=1}^{h} \operatorname{Pr}\left[s_{t}=j, s_{t+1}=i \mid Y_{T}, q, \theta, \equiv\right],
$$

where

$\operatorname{Pr}\left[s_{t}=j, s_{t+1}=i \mid Y_{T}, Q, \theta, \equiv\right]=\frac{\operatorname{Pr}\left[s_{t+1}=i \mid Y_{T}, q, \theta, \Xi\right] \cdot \operatorname{Pr}\left[s_{t}=j \mid Y_{T}, Q, \theta, \equiv\right] \cdot \operatorname{Pr}\left[s_{t+1}=i \mid s_{t}=j\right]}{\operatorname{Pr}\left[s_{t+1}=i \mid Y_{T}, Q, \theta, \equiv\right]}$.

The advantage of such a method is that it allows us to infer the unobservable variable $s_{t}$ using all the information in the sample.

The prior, $p(\theta, \Xi, Q)$ We calibrate some parameters. Following the existing literature, we set the steady share of capital income $(\alpha)$ to 0.30 , the quarterly depreciation rate of capital $(\delta)$ to 0.025 , and the steady state of government spending in total GDP $\left(G_{t} / Y_{t}\right)$ to 0.20 , which is equal to the average value of the sample period. The steady state price $\left(\lambda_{p}\right)$ and wage $\left(\lambda_{w}\right)$ markups are calibrated to 0.20 and 0.35 , respectively.

Tables C.3 and C.4 report the specific distribution, the mean and the standard deviation for each parameter. Most of the prior distributions for the parameters follow those in Smets and Wouters (2007). A few of them deserve further discussion.

First, we consider the prior distributions for parameters in the Taylor rule. The prior for the interest rate response to inflation $\left(\psi_{\pi}\right)$ follows a truncated normal distribution, with 
the mean 1.70 and the standard deviation 0.30 . This prior is rather dispersed and covers a large parameter space. It may be worth noting that the truncation allows to avoid the indeterminacy region of the parameter space. The priors for the interest rate response to output gap $\left(\psi_{X}\right)$ and output gap growth $\left(\psi_{d X}\right)$ follow a gamma distribution, with the mean 0.12 and the standard deviation 0.05. For the smoothing interest rate parameter $\left(\rho_{R}\right)$, we use a beta distribution, with the mean 0.60 and standard deviation 0.20 .

Second, we discuss the prior distributions for the parameters that determine the degree of nominal rigidities. The priors for the Calvo price and wage parameters ( $\xi_{p}$ and $\xi_{w}$ ) follow a beta distribution, with the mean 0.66 and standard deviation 0.10 . This implies that the average durations of price and wage contracts is about three quarters. The priors for the price and wage indexation parameters $\left(\iota_{p}\right.$ and $\left.\iota_{w}\right)$ follow a beta distribution, with the mean 0.50 and standard deviation 0.15 .

Third, the prior distributions of shock processes are weakly informative. For the smoothing parameters, $\rho_{p, t}, \rho_{b, t}, \rho_{z, t}, \rho_{m p, t}, \rho_{w, t}, \rho_{v, t}, \rho_{\mu, t}, \rho_{g, t}$, we use beta distributions, with the mean 0.60 and standard deviation 0.20. Regarding the shock variances, we impose an inverted gamma distribution, where $\ln \left[p_{I G}(\sigma \mid a, b)\right]=a \ln (b)-\ln [\Gamma(a)]-(a+1) \ln (\sigma)-\frac{b}{\sigma}$. The hyper-parameters $(a$ and $b$ ) are 0.2254 , and $1.1244 \mathrm{E}-04$, respectively, meaning a 90 probability interval of $[0.0001 ; 200]$. Following Liu, Waggoner, and Zha (2011), all priors for shock variances remain unchanged across regimes.

Finally, the priors on the transition matrix $\left(q_{i, j}\right)$ follow a dirichlet distribution, with the mean 0.90 and standard deviation 0.06 , implying a prior duration of twelve quarters. Note that the main results remain unchanged when modifying this prior duration.

\section{B.2. A Gibbs-sampler for MS-DSGE models}

Following Bianchi (2013), a Markov Chain Monte Carlo (MCMC) simulation method is employed to approximate the joint posterior density $p\left(\theta, \Xi, q, F_{T}, S_{T} \mid Y_{T}\right)$. More specifically, we can exploit the idea of Gibbs-sampling by sampling alternatively from the following conditional posterior distributions.

Conditional posterior densities, $p\left(\theta \mid Y_{T}, \equiv, Q, F_{T}, S_{T}\right)$. To simulate draws of $\theta$, one can start to use a Random-walk Metropolis-hasting (RWMH) algorithm. For $i=1$ to $N$, here are the following steps of the algorithm

1. Draw $\nu$ from the following proposal distribution

$$
\operatorname{normal}\left(\nu \mid \theta^{i-1}, c^{2} \bar{\Sigma}\right)
$$


where $\bar{\Sigma}$ is the inverse of Hessian at the mode and $c$ is the scale parameter.

2. Calculate the acceptance probability as follows

$$
\alpha=\min \left\{1, \frac{p\left(Y_{T} \mid \nu, \Xi, Q, S_{T}\right) p(\nu)}{p\left(Y_{T} \mid \theta^{i-1}, \Xi, Q, S_{T}\right) p\left(\theta^{i-1}\right)}\right\}
$$

where the conditional likelihood is evaluated using the standard Kalman filter according to the historical path of $S_{T}$.

3. Draw a random number from an uniform distribution defined over the interval $[0,1]$. If the generated number is less than or equal to the calculated value $\alpha$, we set $\theta^{i}=\nu$. Otherwise, $\theta^{i}=\theta^{i-1}$. The rejection probability is chosen to be between 0.70 and 0.75 .

Conditional posterior densities, $p\left(\equiv \mid Y_{T}, Q, F_{T}, S_{T}, \theta\right)$. The distribution for $\sigma_{j}(k)$ is as follows

$$
\operatorname{inv-gamma}\left(\sigma_{j}(k) \mid \tilde{\alpha}_{j}(k), \tilde{\beta}_{j}(k)\right),
$$

with inv-gamma $(x \mid a, b)$ is the inverse gamma distribution of $x$ with $a$ and $b$ as hyperparameters, and

$$
\begin{aligned}
& \tilde{\alpha}_{j}(k)=\bar{\alpha}_{j}+T_{2, k}, \\
& \tilde{\beta}_{j}(k)=\bar{\beta}_{j}+\frac{1}{2} \sum_{t \in\left\{t: s_{t}=k\right\}}\left(f_{t}-G f_{t-1}\right)^{2},
\end{aligned}
$$

with $T_{2, k}$ be the number of elements in $\left\{t: s_{t}=k\right\}$.

Conditional posterior densities, $p\left(F_{T} \mid Y_{T}, Q, \theta, \equiv, S_{T}\right)$. Contrary to the RWMH algorithm, the Gibbs-sampler represents an interesting procedure for approximating the joint posterior distribution because it allows to generate the unobserved DSGE state vector, $F_{T}$. To do so, we employ the Carter and Kohn's multimove Gibbs sampling approach to generate $F_{T}$ from the following joint distribution

$$
p\left(F_{T} \mid Y_{T}\right)=p\left(f_{T} \mid Y_{T}\right) \prod_{t=1}^{T-1} p\left(f_{t} \mid f_{t+1}, Y_{t}\right) .
$$

Consider the following two steps

1. Run the Kalman filter algorithm to obtain $f_{T}$ and its associated variance-covariance matrix, $P_{T \mid T}$, at the last iteration. We have $f_{T \mid T}=\mathrm{E}\left(f_{T} \mid Y_{T}\right)$ and $P_{T \mid T}=\operatorname{var}\left(f_{T} \mid Y_{T}\right)$. Then $f_{T}$ can be generated as follows

$$
f_{T}=\operatorname{normal}\left(f_{T} \mid f_{T, T}, P_{T, T}\right)
$$

2. For $t=T-1, T-2, \cdots, 1$, one can generated $f_{T}$ as follows

$$
f_{t}=\operatorname{normal}\left(f_{t} \mid f_{t \mid t, f_{t+1}}, P_{t \mid t, f_{t+1}}\right) \text {, }
$$


where

$$
\begin{aligned}
& f_{t \mid t, f_{t+1}}=f_{t \mid t}+P_{t \mid t} G^{\prime}\left(G P_{t \mid t} G^{\prime}+Q\left(s_{t}\right)^{-1}\left(f_{t+1}-G f_{t}\right)\right. \\
& P_{t \mid t, f_{t+1}}=P_{t \mid t}-P_{t \mid t} G^{\prime}\left(G P_{t \mid t} G^{\prime}+Q\left(s_{t}\right)\right)^{-1} G P_{t \mid t}
\end{aligned}
$$

Conditional posterior densities, $p\left(S_{T} \mid Y_{T}, q, F_{T}, \theta, \equiv\right)$. When one knows the variable $F_{T}$, the equation (64) can be treated as a Markov-switching VAR model. It follows that one can derive the filtered probabilities of each regime using (64).

Then, for $t=1,2, \ldots, T$, we can generate $S_{t}$ using the Carter and Kohn's multi-move Gibbs-sampling. First, draw $s_{t}$ according to

$$
p\left(s_{t} \mid Y_{T}, Q, \theta, \equiv\right)=\sum_{s_{t+1}} p\left(s_{t} \mid Y_{T}, \theta, \equiv, Q, s_{t+1}\right) p\left(s_{t+1} \mid Y_{T}, \theta, \equiv, Q\right)
$$

where

$$
p\left(s_{t} \mid Y_{T}, \theta, \Xi, Q, s_{t+1}\right)=\frac{\operatorname{Pr}\left[s_{t+1} \mid s_{t}\right] p\left(s_{t} \mid Y_{T}, \theta, \Xi, Q\right)}{p\left(s_{t+1} \mid Y_{t}, \theta, \Xi, Q\right)}
$$

Conditional posterior densities, $p\left(Q \mid Y_{t}, F_{T}, S_{T}, \Xi, \theta\right)$. The conditional posterior distribution of $Q$ is as follows:

$$
p\left(q_{k} \mid S_{T}\right)=\operatorname{dirichlet}\left(q_{k} \mid \alpha_{1 k}+n_{1 k}, \ldots, \alpha_{h k} n_{h k}\right)
$$

where $q_{k}$ is the kth column of $Q, n_{i j}$ is the total number of transitions from state $j$ to state $i$ over the entire sample and $\operatorname{dirichlet}\left(q_{k} \mid \alpha_{1}, \ldots, \alpha_{h}\right)$ is the Dirichlet distribution of $q_{k}$ as follows:

$$
\frac{1}{B(\alpha)} \prod_{i=1}^{h} q_{i}^{\alpha_{i}-1}
$$

with $B(\alpha)=\frac{\prod_{i=1}^{h} \Gamma\left(\alpha_{i}\right)}{\Gamma\left(\sum_{i=1}^{h} \alpha_{i}\right)}$.

\section{B.3. Normalization}

Following Hamilton, Waggoner, and Zha (2007), we normalize the labels of regimes in order to obtain accurate posterior distributions and thus well-defined probability bands for impulse responses, historical decompositions and variance decompositions. For example, in the two-regime models, we impose that shock variances under Regime 1 are larger than those under Regime 2. 


\section{B.4. Inference}

The strategy of estimation begins by generating 100 draws from the prior distribution of each parameter. Each set of points is then used as starting points to the CSMINWEL program, the optimization routine developed by Christopher A. Sims. Starting the optimization process at different values allows us to correctly cover the parameter space and avoid getting stuck in a "local" peak. Once at the posterior mode, we can start a Markov Chain Monte Carlo method to sample the posterior distribution. Following Kim and Nelson (1999) and Bianchi (2013), we employ the Gibbs-sampling procedure to generate draws from the joint posterior distribution of the MS-DSGE models. The results shown in the paper are based on six chains of 200,000 draws, so the total number of draws is 1.2 million. We discarded the first 200, 000 draws (the 50, 000 first of each chain) as burn-in, and every 500th draw is retained. Parallel computing is employed for Bayesian inference. Each chain is allocated to one of the twelve cores of an i7-3930K processor. In MAT$L A B$, we set the seed for a pseudo-random number generator of each chain as follows: $[123 ; 756 ; 345 ; 582 ; 445 ; 875]$ 


\section{Tables and Figures}

Table C.1 - Markov-switching autoregressive parameters (AR coefficient, standard error of the regression, and transition probabilities) for several macroeconomic variables: $\Delta y_{t}=\rho \Delta y_{t-1}+\sigma\left(s_{t}\right) \varepsilon_{t}$.

\begin{tabular}{|c|c|c|c|c|c|c|c|c|c|c|c|c|c|c|c|c|}
\hline \multirow{3}{*}{$p_{11}$} & \multicolumn{2}{|c|}{ Output } & \multicolumn{2}{|c|}{ Consumption } & \multicolumn{2}{|c|}{ Investment } & \multicolumn{2}{|c|}{ Hours } & \multicolumn{2}{|c|}{ Wages } & \multicolumn{2}{|c|}{ Inflation } & \multicolumn{2}{|c|}{ Interest rate } & \multicolumn{2}{|c|}{$\begin{array}{c}\text { Relative Price of } \\
\text { Investment }\end{array}$} \\
\hline & \multicolumn{2}{|c|}{0.91} & \multicolumn{2}{|c|}{0.93} & \multicolumn{2}{|c|}{0.91} & \multicolumn{2}{|c|}{0.93} & \multicolumn{2}{|c|}{0.91} & \multicolumn{2}{|c|}{0.91} & \multicolumn{2}{|c|}{0.92} & \multicolumn{2}{|c|}{0.94} \\
\hline & {$[0.81 ;$} & $0.96]$ & {$[0.85$} & $0.97]$ & {$[0.76$} & $0.98]$ & {$[0.80$} & $0.98]$ & {$[0.83 ;$} & $0.96]$ & {$[0.81$} & $0.97]$ & {$[0.85$} & $0.96]$ & {$[0.87$} & $0.98]$ \\
\hline \multirow[t]{2}{*}{$p_{22}$} & \multicolumn{2}{|c|}{0.93} & \multicolumn{2}{|c|}{0.92} & \multicolumn{2}{|c|}{0.90} & \multicolumn{2}{|c|}{0.90} & \multicolumn{2}{|c|}{0.93} & \multicolumn{2}{|c|}{0.98} & \multicolumn{2}{|c|}{0.94} & \multicolumn{2}{|c|}{0.97} \\
\hline & {$[0.87 ;$} & $0.97]$ & {$[0.85$} & $0.97]$ & {$[0.79$} & $0.97]$ & {$[0.77$} & $0.97]$ & {$[0.86 ;$} & $0.98]$ & {$[0.95$} & $0.99]$ & {$[0.88$} & $0.98]$ & {$[0.92 ;$} & 0.99] \\
\hline \multirow[t]{2}{*}{$\sigma(1)$} & \multicolumn{2}{|c|}{0.64} & \multicolumn{2}{|c|}{0.44} & \multicolumn{2}{|c|}{2.82} & \multicolumn{2}{|c|}{0.25} & \multicolumn{2}{|c|}{0.82} & \multicolumn{2}{|c|}{0.67} & \multicolumn{2}{|c|}{0.91} & \multicolumn{2}{|c|}{0.28} \\
\hline & {$[0.46$} & $0.95]$ & {$[0.33$} & $0.62]$ & {$[1.99 ;$} & $6.94]$ & {$[0.19 ;$} & $0.46]$ & {$[0.60 ;$} & $1.17]$ & {$[0.42$} & $1.20]$ & {$[0.65 ;$} & $1.32]$ & {$[0.20$} & $0.43]$ \\
\hline$\sigma(2)$ & 0 & & 0. & & 0. & & & & & & 0. & & & & & \\
\hline & {$[0.07 ;$} & $0.14]$ & {$[0.05$} & $0.10]$ & {$[0.31$} & $1.59]$ & {$[0.01$} & $0.19]$ & {$[0.07 ;$} & $0.16]$ & {$[0.06$} & $0.09]$ & {$[0.08$} & $0.19]$ & {$[0.06 ;$} & $0.10]$ \\
\hline$\rho$ & & & 0. & & 0. & & 0. & & & & 0. & & & & & \\
\hline & {$[0.36$} & $0.60]$ & {$[-0.02$} & $0.25]$ & {$[0.22$} & $0.46]$ & {$[0.25$} & $0.49]$ & {$[0.84$} & $0.95]$ & {$[0.88$} & $0.97]$ & {$[0.97$} & $1.01]$ & {$[0.21 ;$} & $0.46]$ \\
\hline
\end{tabular}


Table C.2 - Measure of fit

\begin{tabular}{llc}
\hline \hline Model & Specification & Log MDD \\
\hline $\mathfrak{M}_{\text {constant }}$ & Time-invariant model & -927.17 \\
$\mathfrak{M}_{2 \mathrm{v}}$ & Two regimes in shock variances & -869.42 \\
$\mathfrak{M}_{3 \mathrm{v}}$ & Three regimes in shock variances & $* * *$ \\
$\mathfrak{M}_{2 \mathrm{MEI}-\mathrm{v}}$ & Two regimes in MEl shock variance & -929.59 \\
$\mathfrak{M}_{2 \text { TECH-v }}$ & Two regimes in Neutral and IST shock variances & -922.64 \\
& & \\
$\mathfrak{M}_{2 \mathrm{v}+\mathrm{Mp}}$ & Two regimes in shock variances & -892.98 \\
& ans a single break in monetary policy & \\
\hline
\end{tabular}

Note: The method for computing marginal data densities is the Meng and Wong (1996) method.

Table C.3 - Prior and Posterior Distribution (continued on the next page)

\begin{tabular}{|c|c|c|c|c|c|c|c|}
\hline \multirow[b]{2}{*}{ Coefficient } & \multirow[b]{2}{*}{ Description } & \multicolumn{3}{|c|}{ Prior } & \multicolumn{3}{|c|}{ Posterior } \\
\hline & & Density & $\operatorname{para}(1)$ & $\operatorname{para}(2)$ & Median & {$[5 ;$} & 95] \\
\hline$\alpha$ & Capital share & $\mathrm{N}$ & 0.3000 & 0.0500 & 0.2524 & 0.2259 & 0.2793 \\
\hline$\iota_{p}$ & Price indexation & B & 0.5000 & 0.1500 & 0.1624 & 0.0627 & 0.2714 \\
\hline$\iota_{w}$ & Wage indexation & B & 0.5000 & 0.1500 & 0.0621 & 0.0266 & 0.0986 \\
\hline $100 \gamma^{*}$ & SS composite growth rate & $\mathrm{N}$ & 0.3500 & 0.0250 & 0.3352 & 0.2953 & 0.3724 \\
\hline $100 \gamma^{\mu}$ & SS IST growth rate & $\mathrm{N}$ & 0.0500 & 0.0250 & 0.0707 & 0.0399 & 0.1047 \\
\hline$h$ & Consumption habit & B & 0.5000 & 0.1000 & 0.4642 & 0.3786 & 0.5538 \\
\hline $\ln L^{s s}$ & SS log-hours & N & 0.0000 & 0.0250 & -0.0003 & -0.0417 & 0.0397 \\
\hline $100(\pi-1)$ & SS quarterly inflation & N & 1.2500 & 0.1000 & 1.2006 & 1.0415 & 1.3687 \\
\hline $100\left(\beta^{-1}-1\right)$ & Discount factor & B & 0.2500 & 0.1000 & 0.1439 & 0.0667 & 0.2302 \\
\hline$\nu$ & Inverse Frish elasticity & G & 2.0000 & 0.7500 & 4.8896 & 3.4371 & 6.3441 \\
\hline$\xi_{p}$ & Calvo prices & B & 0.6600 & 0.1000 & 0.9276 & 0.9058 & 0.9475 \\
\hline$\xi_{w}$ & Calvo wages & B & 0.6600 & 0.1000 & 0.8397 & 0.7811 & 0.8933 \\
\hline$x$ & Elas. capital utilization costs & G & 5.0000 & 0.5000 & 5.0681 & 4.2627 & 5.8728 \\
\hline$S^{\prime \prime}$ & Investment adjustment costs & G & 4.0000 & 1.0000 & 7.0788 & 5.3615 & 8.9534 \\
\hline$\phi_{\pi}$ & Taylor rule inflation & $\mathrm{N}$ & 1.7000 & 0.3000 & 1.8288 & 1.5272 & 2.1487 \\
\hline$\phi_{X}$ & Taylor rule output & $\mathrm{N}$ & 0.1250 & 0.0500 & 0.1166 & 0.0601 & 0.1787 \\
\hline$\phi_{d x}$ & Taylor rule output growth & $\mathrm{N}$ & 0.1250 & 0.0500 & 0.2795 & 0.2272 & 0.3273 \\
\hline$\rho_{R}$ & Taylor rule smoothing & B & 0.6000 & 0.2000 & 0.9225 & 0.8977 & 0.9448 \\
\hline$\rho_{z}$ & Neutral technology growth & B & 0.4000 & 0.2000 & 0.1079 & 0.0356 & 0.1808 \\
\hline$\rho_{\mu}$ & IST & B & 0.2000 & 0.1000 & 0.2662 & 0.1586 & 0.3736 \\
\hline$\rho_{\lambda_{p}}$ & Price markup & B & 0.6000 & 0.2000 & 0.7755 & 0.6386 & 0.8854 \\
\hline$\rho_{\lambda_{w}}$ & Wage markup & B & 0.6000 & 0.2000 & 0.9864 & 0.9753 & 0.9967 \\
\hline$\rho_{b}$ & Intertemporal preference & B & 0.6000 & 0.2000 & 0.8481 & 0.7870 & 0.9009 \\
\hline$\theta_{p}$ & Price markup MA & B & 0.5000 & 0.2000 & 0.6787 & 0.4855 & 0.8382 \\
\hline$\theta_{w}$ & Wage markup MA & B & 0.5000 & 0.2000 & 0.9563 & 0.9374 & 0.9739 \\
\hline$\rho_{\mathrm{MEI}}$ & MEI & B & 0.6000 & 0.2000 & 0.6061 & 0.5354 & 0.6770 \\
\hline
\end{tabular}


Table C.4 - Prior and Posterior Distribution (continued from previous page)

\begin{tabular}{|c|c|c|c|c|c|c|c|}
\hline \multirow[b]{2}{*}{ Coefficient } & \multirow[b]{2}{*}{ Description } & \multicolumn{3}{|c|}{ Prior } & \multicolumn{3}{|c|}{ Posterior } \\
\hline & & Density & para(1) & para(2) & Median & {$[5$} & 95] \\
\hline $100 \sigma_{m p}\left(s_{t}=1\right)$ & Monetary policy & Inv-G & 0.2254 & $1.1244 \mathrm{E}-04$ & 0.2189 & 0.1872 & 0.2527 \\
\hline $100 \sigma_{m p}\left(s_{t}=2\right)$ & Monetary policy & Inv-G & 0.2254 & $1.1244 \mathrm{E}-04$ & 0.1295 & 0.1066 & 0.1524 \\
\hline $100 \sigma_{z}\left(s_{t}=1\right)$ & Neutral technology growth & Inv-G & 0.2254 & $1.1244 \mathrm{E}-04$ & 1.0188 & 0.8696 & 1.1770 \\
\hline $100 \sigma_{z}\left(s_{t}=2\right)$ & Neutral technology growth & Inv-G & 0.2254 & $1.1244 \mathrm{E}-04$ & 0.7060 & 0.6022 & 0.8127 \\
\hline $100 \sigma_{g}\left(s_{t}=1\right)$ & Government spending & Inv-G & 0.2254 & $1.1244 \mathrm{E}-04$ & 0.6781 & 0.5844 & 0.7777 \\
\hline $100 \sigma_{g}\left(s_{t}=2\right)$ & Government spending & Inv-G & 0.2254 & 1.1244E-04 & 0.3422 & 0.2903 & 0.3950 \\
\hline $100 \sigma_{\mu}\left(s_{t}=1\right)$ & IST & Inv-G & 0.2254 & $1.1244 \mathrm{E}-04$ & 0.4909 & 0.4209 & 0.5621 \\
\hline $100 \sigma_{\mu}\left(s_{t}=2\right)$ & IST & Inv-G & 0.2254 & $1.1244 \mathrm{E}-04$ & 0.2537 & 0.2228 & 0.2886 \\
\hline $100 \sigma_{p}\left(s_{t}=1\right)$ & Price markup & Inv-G & 0.2254 & $1.1244 \mathrm{E}-04$ & 0.2690 & 0.2163 & 0.3239 \\
\hline $100 \sigma_{p}\left(s_{t}=2\right)$ & Price markup & Inv-G & 0.2254 & $1.1244 \mathrm{E}-04$ & 0.1431 & 0.1196 & 0.1675 \\
\hline $100 \sigma_{w}\left(s_{t}=1\right)$ & Wage markup & Inv-G & 0.2254 & $1.1244 \mathrm{E}-04$ & 0.2339 & 0.1918 & 0.2772 \\
\hline $100 \sigma_{w}\left(s_{t}=2\right)$ & Wage markup & Inv-G & 0.2254 & $1.1244 \mathrm{E}-04$ & 0.0982 & 0.0803 & 0.1155 \\
\hline $100 \sigma_{b}\left(s_{t}=1\right)$ & Intertemporal preference & Inv-G & 0.2254 & $1.1244 \mathrm{E}-04$ & 0.0484 & 0.0337 & 0.0639 \\
\hline $100 \sigma_{b}\left(s_{t}=2\right)$ & Intertemporal preference & Inv-G & 0.2254 & 1.1244E-04 & 0.0253 & 0.0182 & 0.0330 \\
\hline $100 \sigma_{\mathrm{MEI}}\left(s_{t}=2\right)$ & MEI & Inv-G & 0.2254 & $1.1244 \mathrm{E}-04$ & 8.2784 & 6.1955 & 10.5877 \\
\hline $100 \sigma_{\mathrm{MEI}}\left(s_{t}=2\right)$ & $\mathrm{MEI}$ & Inv-G & 0.2254 & $1.1244 \mathrm{E}-04$ & 5.4742 & 4.0309 & 7.0887 \\
\hline$p_{11}$ & proba. moving from 1 to 1 & D & 0.9000 & 0.0600 & 0.9021 & 0.8417 & 0.9536 \\
\hline$p_{22}$ & proba. moving from 2 to 2 & $\mathrm{D}$ & 0.9000 & 0.0600 & 0.9133 & 0.8635 & 0.9559 \\
\hline
\end{tabular}

Note: $\mathrm{N}$ stands for Normal, B Beta, G for Gamma, Inv-G for Inverted-Gamma and D for Dirichlet distributions. The 5 percent and 95 percent demarcate the bounds of the 90 percent probability interval. Para(1) and Para(2) correspond to the means and standard deviations for the normal, beta, gamma, dirichlet distributions and to $a$ and $b$ for the inverted-gamma distribution, where $\ln \left[p_{I G}(\sigma \mid a, b)\right]=a \ln (b)-\ln [\Gamma(a)]-(a+1) \ln (\sigma)-\frac{b}{\sigma}$. 
Table C.5 - Posterior variance decomposition for observable variables in the High-volatility regime

\begin{tabular}{|c|c|c|c|c|c|c|c|c|c|c|c|c|c|c|c|c|}
\hline \multirow{3}{*}{$Y_{t}^{\text {Data }}$} & \multicolumn{2}{|c|}{ Monetary } & \multicolumn{2}{|c|}{ Neutral } & \multicolumn{2}{|c|}{ Government } & \multicolumn{2}{|c|}{ IST } & \multicolumn{2}{|c|}{$\begin{array}{c}\text { Price } \\
\text { markup }\end{array}$} & \multicolumn{2}{|c|}{$\begin{array}{l}\text { Wage } \\
\text { markup }\end{array}$} & \multicolumn{2}{|c|}{ Preference } & \multicolumn{2}{|c|}{$\mathrm{MEI}$} \\
\hline & \multicolumn{2}{|c|}{14.29} & \multicolumn{2}{|c|}{22.65} & \multicolumn{2}{|c|}{18.98} & \multicolumn{2}{|c|}{1.51} & \multicolumn{2}{|c|}{1.66} & \multicolumn{2}{|c|}{3.69} & \multicolumn{2}{|c|}{11.26} & \multicolumn{2}{|c|}{24.18} \\
\hline & {$[10.45$} & 19.28] & {$[16.12 ;$} & $31.47]$ & [13.68; & $25.59]$ & {$[1.03$} & $2.20]$ & {$[0.89$} & 3.09] & {$[2.13$} & $6.11]$ & {$[7.63$} & $16.09]$ & {$[17.42$} & $32.70]$ \\
\hline \multirow[t]{2}{*}{$C_{t}^{\text {Data }}$} & \multicolumn{2}{|c|}{11.33} & \multicolumn{2}{|c|}{25.19} & \multicolumn{2}{|c|}{17.82} & \multicolumn{2}{|c|}{0.19} & \multicolumn{2}{|c|}{0.25} & \multicolumn{2}{|c|}{3.01} & \multicolumn{2}{|c|}{31.83} & \multicolumn{2}{|c|}{8.56} \\
\hline & {$[7.81$} & 16.20] & {$[18.64 ;$} & 33.35] & {$[12.67$; } & $24.08]$ & {$[0.11$} & $0.34]$ & {$[0.08$} & $0.74]$ & {$[1.77$} & 5.32] & {$[23.15 ;$} & 43.15] & {$[5.08$} & 13.82] \\
\hline \multirow[t]{2}{*}{$I_{t}^{\text {Data }}$} & \multicolumn{2}{|c|}{4.28} & \multicolumn{2}{|c|}{3.44} & \multicolumn{2}{|c|}{0.04} & \multicolumn{2}{|c|}{2.64} & \multicolumn{2}{|c|}{1.74} & & & & & 79. & \\
\hline & {$[2.68$} & 6.62] & {$[2.21$} & 5.33] & {$[0.02$} & $0.10]$ & {$[1.79$} & $3.86]$ & {$[1.01$} & $3.06]$ & {$[3.08$} & $9.92]$ & {$[1.02 ;$} & $3.61]$ & {$[73.13$} & 84.90] \\
\hline$W_{t}^{\text {Data }}$ & & & & & & & 0. & & & & 56 & & & & 0.6 & \\
\hline & {$[0.14$} & $2.23]$ & {$[6.57$} & $14.68]$ & {$[0.00$} & $0.02]$ & {$[0.09$} & $0.23]$ & [23.66; & $40.11]$ & [46.88; & 65.40] & {$[0.01 ;$} & $0.42]$ & {$[0.27$} & 1.66] \\
\hline$L_{t}^{\text {Data }}$ & & & & & & & 0. & & & & 4. & & & & 24. & \\
\hline & {$[11.61 ;$} & 22.52] & {$[11.45 ;$} & 22.79] & {$[16.04$} & 28.06] & {$[0.59$} & $1.30]$ & {$[0.93$} & $3.45]$ & {$[2.77$} & $7.41]$ & {$[8.54 ;$} & $17.67]$ & {$[17.44$} & 32.69] \\
\hline$\Pi_{t}^{\text {Data }}$ & & & & & & & 0 & & & & 73 & & & & 0.1 & \\
\hline & {$[0.50$} & $5.08]$ & {$[0.34$} & $2.05]$ & {$[0.05$} & $0.27]$ & {$[0.00$} & $0.09]$ & {$[14.62 ;$} & 33.49] & [61.63; & 82.78] & {$[0.04$} & $0.85]$ & {$[0.00$} & $0.17]$ \\
\hline$R_{t}^{\text {Data }}$ & & & & & & & 0. & & & & 65 & & & & 12. & \\
\hline & {$[2.67 ;$} & $7.16]$ & {$[1.41 ;$} & $4.04]$ & {$[0.69 ;$} & $1.91]$ & {$[0.22$} & $0.72]$ & {$[0.79$} & $2.78]$ & {$[50.38$} & $77.26]$ & {$[6.50 ;$} & $17.98]$ & {$[7.40$} & $20.71]$ \\
\hline$P_{l t}^{\text {Data }}$ & & & & & & & 100 & & & & & & & & 0. & \\
\hline & {$[0.00$} & $0.00]$ & {$[0.00$} & $0.00]$ & {$[0.00$} & $0.00]$ & {$[100.00$} & $100.00]$ & {$[0.00$} & $0.00]$ & {$[0.00$} & $0.00]$ & {$[0.00 ;$} & $0.00]$ & {$[0.00$} & $0.00]$ \\
\hline
\end{tabular}


Table C.6 - Posterior variance decomposition for observable variables in the Low-volatility regime

\begin{tabular}{|c|c|c|c|c|c|c|c|c|c|c|c|c|c|c|c|c|}
\hline & \multicolumn{2}{|c|}{ Monetary } & \multicolumn{2}{|c|}{ Neutral } & \multicolumn{2}{|c|}{ Government } & \multicolumn{2}{|c|}{ IST } & \multicolumn{2}{|c|}{$\begin{array}{c}\text { Price } \\
\text { markup }\end{array}$} & \multicolumn{2}{|c|}{$\begin{array}{l}\text { Wage } \\
\text { markup }\end{array}$} & \multicolumn{2}{|c|}{ Preference } & \multicolumn{2}{|c|}{ MEl } \\
\hline \multirow[t]{2}{*}{$Y_{t}^{\text {Data }}$} & \multicolumn{2}{|c|}{13.67} & \multicolumn{2}{|c|}{30.05} & \multicolumn{2}{|c|}{13.32} & \multicolumn{2}{|c|}{1.10} & \multicolumn{2}{|c|}{1.30} & \multicolumn{2}{|c|}{1.78} & \multicolumn{2}{|c|}{8.39} & \multicolumn{2}{|c|}{29.16} \\
\hline & {$[10.45$} & $19.28]$ & {$[22.54$} & 38.90] & {$[9.45$} & 18.33] & {$[0.78$} & $1.56]$ & {$[0.62$} & $2.66]$ & {$[1.02$} & $3.04]$ & {$[5.63$} & 12.20] & [21.28; & 37.96] \\
\hline \multirow{2}{*}{$C_{t}^{\text {Data }}$} & \multicolumn{2}{|c|}{11.53} & \multicolumn{2}{|c|}{35.44} & \multicolumn{2}{|c|}{13.31} & \multicolumn{2}{|c|}{0.15} & \multicolumn{2}{|c|}{0.21} & \multicolumn{2}{|c|}{1.56} & \multicolumn{2}{|c|}{25.45} & \multicolumn{2}{|c|}{10.94} \\
\hline & {$[7.81$} & $16.20]$ & {$[27.78$} & 43.80] & {$[9.61$} & 18.08] & {$[0.09$} & $0.26]$ & {$[0.06$} & 0.69] & {$[0.90$} & $2.81]$ & {$[17.51 ;$} & $35.66]$ & {$[6.68 ;$} & $16.94]$ \\
\hline \multirow[t]{2}{*}{$I_{t}^{\text {Data }}$} & \multicolumn{2}{|c|}{3.61} & \multicolumn{2}{|c|}{4.05} & \multicolumn{2}{|c|}{0.03} & \multicolumn{2}{|c|}{1.71} & \multicolumn{2}{|c|}{1.20} & & & & & 85 & \\
\hline & {$[2.68$} & $6.62]$ & {$[2.58$} & $6.22]$ & {$[0.01$} & $0.06]$ & {$[1.18$} & 2.47] & {$[0.65$} & $2.26]$ & {$[1.34$} & 4.35] & {$[0.66$} & $2.50]$ & [80.29; & 89.24] \\
\hline$W_{t}^{\text {Data }}$ & & & 19 & & 0. & & 0. & & & & & & & & 1. & \\
\hline & {$[0.14$} & 2.23] & [13.28; & $27.55]$ & {$[0.00$} & $0.02]$ & {$[0.10$} & $0.25]$ & [28.10; & 45.38] & {$[31.46$} & 50.93] & {$[0.01 ;$} & $0.44]$ & {$[0.52$} & $2.76]$ \\
\hline$L_{t}^{\text {Data }}$ & & & & & 15 & & 0. & & & & & & & & 30 & \\
\hline & [11.61; & 22.52] & {$[15.73$} & $30.02]$ & [11.54; & $20.55]$ & {$[0.47$} & $0.94]$ & {$[0.67$} & $3.05]$ & {$[1.39 ;$} & $3.79]$ & {$[6.52 ;$} & 13.92] & {$[22.23$} & 39.03] \\
\hline$\Pi_{t}^{\text {Data }}$ & & & & & 0. & & 0. & & & & 62 & & & & 0. & \\
\hline & {$[0.50$} & $5.08]$ & {$[0.76$} & $4.73]$ & {$[0.07$} & $0.31]$ & {$[0.00 ;$} & $0.10]$ & [21.38; & 41.88] & [49.46; & 73.92] & {$[0.05 ;$} & $1.05]$ & {$[0.01 ;$} & $0.35]$ \\
\hline$R_{t}^{\text {Data }}$ & & & & & 1. & & 0. & & & & 48 & & & & 23 & \\
\hline & {$[2.67$} & $7.16]$ & {$[2.95$} & 7.50] & {$[0.80$} & $1.91]$ & {$[0.27$} & $0.75]$ & {$[1.02 ;$} & $3.13]$ & [33.83; & 62.03] & [8.04; & 19.17] & {$[14.77$} & 34.30] \\
\hline$P_{l t}^{\text {Data }}$ & & & & & 0. & & 100 & 00 & & & 0 & & & & 0. & \\
\hline & {$[0.00$} & $0.00]$ & {$[0.00$} & $0.00]$ & {$[0.00$} & $0.00]$ & [100.00; & $100.00]$ & {$[0.00$} & $0.00]$ & {$[0.00$} & $0.00]$ & {$[0.00$} & $0.00]$ & {$[0.00$} & $0.00]$ \\
\hline
\end{tabular}


Table C.7 - Prior and Posterior Distribution (continued on the next page)

\begin{tabular}{|c|c|c|c|c|c|c|c|}
\hline \multirow[b]{2}{*}{ Coefficient } & \multirow[b]{2}{*}{ Description } & \multicolumn{3}{|c|}{ Prior } & \multicolumn{3}{|c|}{ Posterior } \\
\hline & & Density & para(1) & para(2) & Median & {$[5$} & 95] \\
\hline$\alpha$ & Capital share & $\mathrm{N}$ & 0.3000 & 0.0500 & 0.2500 & 0.2231 & 0.2774 \\
\hline$\iota_{p}$ & Price indexation & B & 0.5000 & 0.1500 & 0.1756 & 0.0710 & 0.2969 \\
\hline$\iota_{w}$ & Wage indexation & $B$ & 0.5000 & 0.1500 & 0.0719 & 0.0329 & 0.1156 \\
\hline $100 \gamma^{*}$ & SS composite growth rate & $\mathrm{N}$ & 0.3500 & 0.0250 & 0.3379 & 0.3006 & 0.3772 \\
\hline $100 \gamma^{\mu}$ & SS IST growth rate & $\mathrm{N}$ & 0.0500 & 0.0250 & 0.0701 & 0.0361 & 0.1030 \\
\hline$h$ & Consumption habit & B & 0.5000 & 0.1000 & 0.4686 & 0.3734 & 0.5700 \\
\hline $\ln L^{s s}$ & SS log-hours & $\mathrm{N}$ & 0.0000 & 0.0250 & -0.0006 & -0.0407 & 0.0414 \\
\hline $100(\pi-1)$ & SS quarterly inflation & N & 1.2500 & 0.1000 & 1.1513 & 0.9840 & 1.3105 \\
\hline $100\left(\beta^{-1}-1\right)$ & Discount factor & B & 0.2500 & 0.1000 & 0.1400 & 0.0579 & 0.2201 \\
\hline$\nu$ & Inverse Frish elasticity & G & 2.0000 & 0.7500 & 4.8759 & 3.4265 & 6.4401 \\
\hline$\xi_{p}$ & Calvo prices & B & 0.6600 & 0.1000 & 0.9319 & 0.9096 & 0.9514 \\
\hline$\xi_{w}$ & Calvo wages & B & 0.6600 & 0.1000 & 0.8229 & 0.7686 & 0.8743 \\
\hline$x$ & Elas. capital utilization costs & G & 5.0000 & 0.5000 & 5.0890 & 4.2525 & 5.8994 \\
\hline$S^{\prime \prime}$ & Investment adjustment costs & G & 4.0000 & 1.0000 & 7.0147 & 5.3356 & 8.7519 \\
\hline$\phi_{\pi}^{1}$ & Taylor rule inflation(1st sample) & $\mathrm{N}$ & 1.7000 & 0.3000 & 1.5563 & 1.2294 & 1.8982 \\
\hline$\phi_{\pi}^{2}$ & Taylor rule inflation(2nd sample) & $\mathrm{N}$ & 1.7000 & 0.3000 & 1.8884 & 1.5397 & 2.2439 \\
\hline$\phi_{X}^{1}$ & Taylor rule output(1st sample) & $\mathrm{N}$ & 0.1250 & 0.0500 & 0.1682 & 0.1000 & 0.2332 \\
\hline$\phi_{X}^{2}$ & Taylor rule output(2nd sample) & $\mathrm{N}$ & 0.1250 & 0.0500 & 0.0966 & 0.0449 & 0.1527 \\
\hline$\phi_{d x}^{1}$ & Taylor rule output growth(1st sample) & N & 0.1250 & 0.0500 & 0.2843 & 0.2226 & 0.3453 \\
\hline$\phi_{d x}^{2}$ & Taylor rule output growth(2nd sample) & $\mathrm{N}$ & 0.1250 & 0.0500 & 0.2092 & 0.1600 & 0.2561 \\
\hline$\rho_{R}^{1}$ & Taylor rule smoothing(1st sample) & B & 0.6000 & 0.2000 & 0.9096 & 0.8823 & 0.9356 \\
\hline$\rho_{R}^{2}$ & Taylor rule smoothing(2nd sample) & B & 0.6000 & 0.2000 & 0.9217 & 0.8942 & 0.9476 \\
\hline$\rho_{z}$ & Neutral technology growth & B & 0.4000 & 0.2000 & 0.1126 & 0.0348 & 0.1899 \\
\hline$\rho_{\mu}$ & IST & B & 0.2000 & 0.1000 & 0.2658 & 0.1523 & 0.3751 \\
\hline$\rho_{\lambda_{p}}$ & Price markup & B & 0.6000 & 0.2000 & 0.7299 & 0.5581 & 0.8745 \\
\hline$\rho_{\lambda_{w}}$ & Wage markup & B & 0.6000 & 0.2000 & 0.9881 & 0.9781 & 0.9970 \\
\hline$\rho_{b}$ & Intertemporal preference & B & 0.6000 & 0.2000 & 0.8154 & 0.7365 & 0.8843 \\
\hline$\theta_{p}$ & Price markup MA & B & 0.5000 & 0.2000 & 0.6346 & 0.4092 & 0.8219 \\
\hline$\theta_{w}$ & Wage markup MA & B & 0.5000 & 0.2000 & 0.9610 & 0.9438 & 0.9772 \\
\hline$\rho_{\mathrm{MEI}}$ & MEl & B & 0.6000 & 0.2000 & 0.6013 & 0.5334 & 0.6779 \\
\hline
\end{tabular}


Table C.8 - Prior and Posterior Distribution (continued from previous page)

\begin{tabular}{|c|c|c|c|c|c|c|c|}
\hline \multirow[b]{2}{*}{ Coefficient } & \multirow[b]{2}{*}{ Description } & \multicolumn{3}{|c|}{ Prior } & \multicolumn{3}{|c|}{ Posterior } \\
\hline & & Density & para $(1)$ & $\operatorname{para}(2)$ & Median & {$[5$} & 95] \\
\hline $100 \sigma_{m p}\left(s_{t}=1\right)$ & Monetary policy & Inv-G & 0.2254 & $1.1244 \mathrm{E}-04$ & 0.2265 & 0.1906 & 0.2637 \\
\hline $100 \sigma_{m p}\left(s_{t}=2\right)$ & Monetary policy & Inv-G & 0.2254 & 1.1244E-04 & 0.1190 & 0.0980 & 0.1409 \\
\hline $100 \sigma_{z}\left(s_{t}=1\right)$ & Neutral technology growth & Inv-G & 0.2254 & $1.1244 \mathrm{E}-04$ & 0.9734 & 0.8338 & 1.1307 \\
\hline $100 \sigma_{z}\left(s_{t}=2\right)$ & Neutral technology growth & Inv-G & 0.2254 & 1.1244E-04 & 0.7528 & 0.6513 & 0.8565 \\
\hline $100 \sigma_{g}\left(s_{t}=1\right)$ & Government spending & Inv-G & 0.2254 & 1.1244E-04 & 0.6592 & 0.5674 & 0.7633 \\
\hline $100 \sigma_{g}\left(s_{t}=2\right)$ & Government spending & Inv-G & 0.2254 & 1.1244E-04 & 0.3850 & 0.3269 & 0.4540 \\
\hline $100 \sigma_{\mu}\left(s_{t}=1\right)$ & IST & Inv-G & 0.2254 & 1.1244E-04 & 0.4863 & 0.4154 & 0.5640 \\
\hline $100 \sigma_{\mu}\left(s_{t}=2\right)$ & IST & Inv-G & 0.2254 & 1.1244E-04 & 0.2722 & 0.2384 & 0.3081 \\
\hline $100 \sigma_{p}\left(s_{t}=1\right)$ & Price markup & Inv-G & 0.2254 & 1.1244E-04 & 0.2524 & 0.2011 & 0.3063 \\
\hline $100 \sigma_{p}\left(s_{t}=2\right)$ & Price markup & Inv-G & 0.2254 & 1.1244E-04 & 0.1723 & 0.1386 & 0.2071 \\
\hline $100 \sigma_{w}\left(s_{t}=1\right)$ & Wage markup & Inv-G & 0.2254 & $1.1244 \mathrm{E}-04$ & 0.2207 & 0.1797 & 0.2634 \\
\hline $100 \sigma_{w}\left(s_{t}=2\right)$ & Wage markup & Inv-G & 0.2254 & $1.1244 \mathrm{E}-04$ & 0.1251 & 0.1017 & 0.1488 \\
\hline $100 \sigma_{b}\left(s_{t}=1\right)$ & Intertemporal preference & Inv-G & 0.2254 & 1.1244E-04 & 0.0558 & 0.0392 & 0.0739 \\
\hline $100 \sigma_{b}\left(s_{t}=2\right)$ & Intertemporal preference & Inv-G & 0.2254 & 1.1244E-04 & 0.0320 & 0.0229 & 0.0428 \\
\hline $100 \sigma_{\mathrm{MEI}}\left(s_{t}=2\right)$ & $\mathrm{MEI}$ & Inv-G & 0.2254 & $1.1244 \mathrm{E}-04$ & 7.3650 & 5.5718 & 9.3326 \\
\hline $100 \sigma_{\mathrm{MEI}}\left(s_{t}=2\right)$ & MEI & Inv-G & 0.2254 & $1.1244 \mathrm{E}-04$ & 6.1099 & 4.4401 & 7.6950 \\
\hline$p_{11}$ & proba. moving from 1 to 1 & $\mathrm{D}$ & 0.9000 & 0.0600 & 0.9161 & 0.8573 & 0.9663 \\
\hline$p_{22}$ & proba. moving from 2 to 2 & $\mathrm{D}$ & 0.9000 & 0.0600 & 0.9288 & 0.8828 & 0.9719 \\
\hline
\end{tabular}

Note: $\mathrm{N}$ stands for Normal, B Beta, G for Gamma, Inv-G for Inverted-Gamma and D for Dirichlet distributions. The 5 percent and 95 percent demarcate the bounds of the 90 percent probability interval. Para(1) and Para(2) correspond to the means and standard deviations for the normal, beta, gamma, dirichlet distributions and to $a$ and $b$ for the inverted-gamma distribution, where $\ln \left[p_{I G}(\sigma \mid a, b)\right]=a \ln (b)-\ln [\Gamma(a)]-(a+1) \ln (\sigma)-\frac{b}{\sigma}$.

\section{Table C.9 - Counterfactual Standard Deviations (STD) of Output and In-} flation

\begin{tabular}{|c|c|c|c|c|c|c|}
\hline & \multicolumn{4}{|c|}{ Model-implied STD } & \multirow{2}{*}{\multicolumn{2}{|c|}{$\begin{array}{c}\text { Counterfactual } \\
(3)\end{array}$}} \\
\hline & \multicolumn{2}{|c|}{ (1) } & \multicolumn{2}{|c|}{ (2) } & & \\
\hline & \multicolumn{2}{|c|}{ Pre-1993 } & \multicolumn{2}{|c|}{ Post-1993 } & \multicolumn{2}{|c|}{ Monetary policy } \\
\hline Output & \multicolumn{2}{|c|}{0.82} & \multicolumn{2}{|c|}{0.72} & \multicolumn{2}{|c|}{0.90} \\
\hline median and $90 \%$ probability interval & {$[0.76$} & 0.89] & {$[0.67$} & $0.79]$ & {$[0.84$} & $0.99]$ \\
\hline Inflation & \multicolumn{2}{|c|}{0.62} & \multicolumn{2}{|c|}{0.35} & \multicolumn{2}{|c|}{0.47} \\
\hline median and $90 \%$ probability interval & {$[0.53$} & $0.75]$ & {$[0.31 ;$} & $0.42]$ & {$[0.40$} & $0.56]$ \\
\hline
\end{tabular}

Note: Standard deviations (STD) are estimated for output and inflation under several specifications. Column (1): STD implied by the first halve of the sample (pre-1993). Column (2): STD implied by the second halve of the sample(post1993). Column (3): STD when the estimated monetary policy coefficients of the first halve of the sample is replaced by those estimated in the second halve of the sample. 

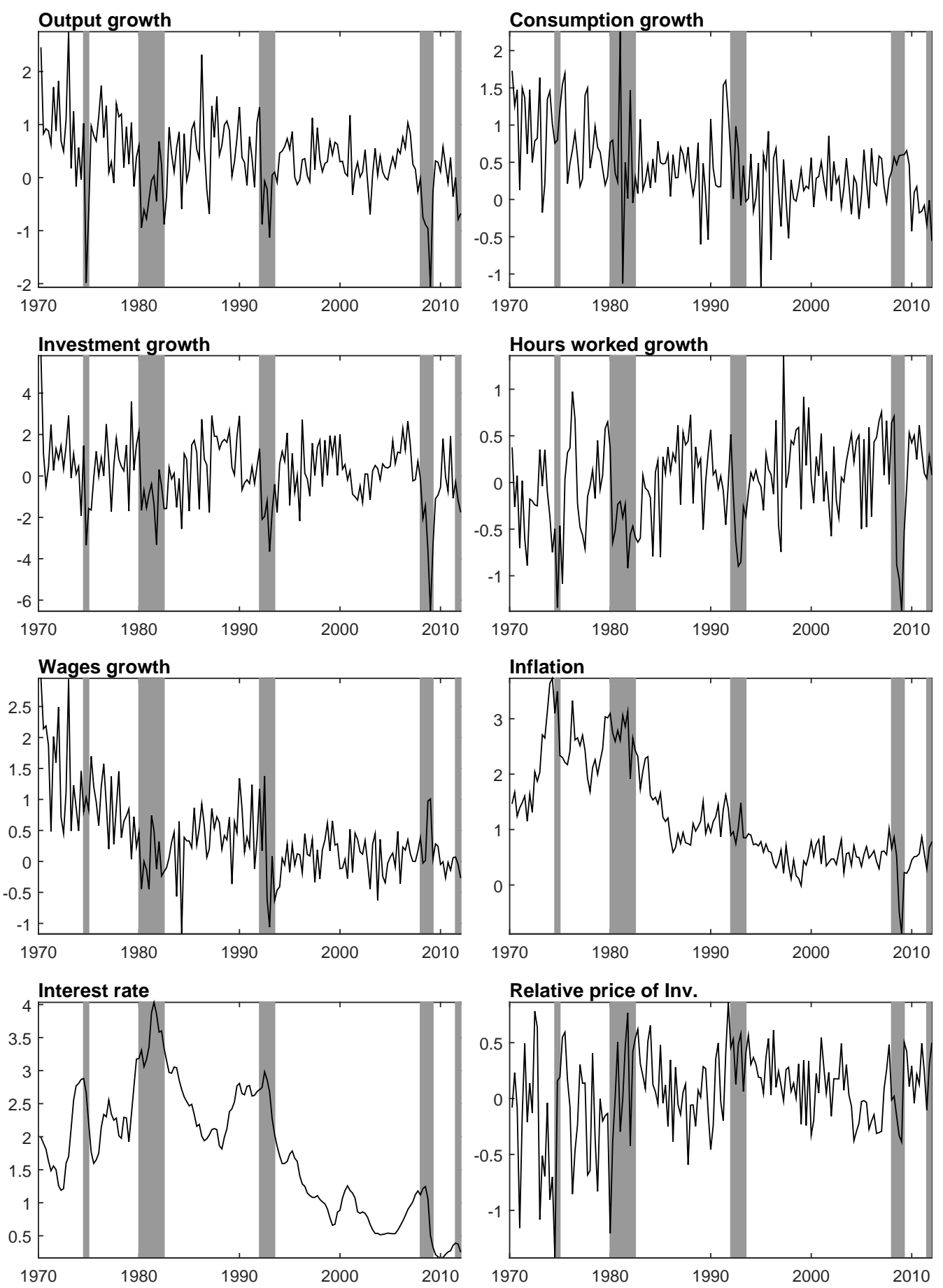

Figure C.1 - Sample period: 1970.Q2-2012.Q1. Time series of observable variables. The grey area denotes CEPR recessions of the euro area. 

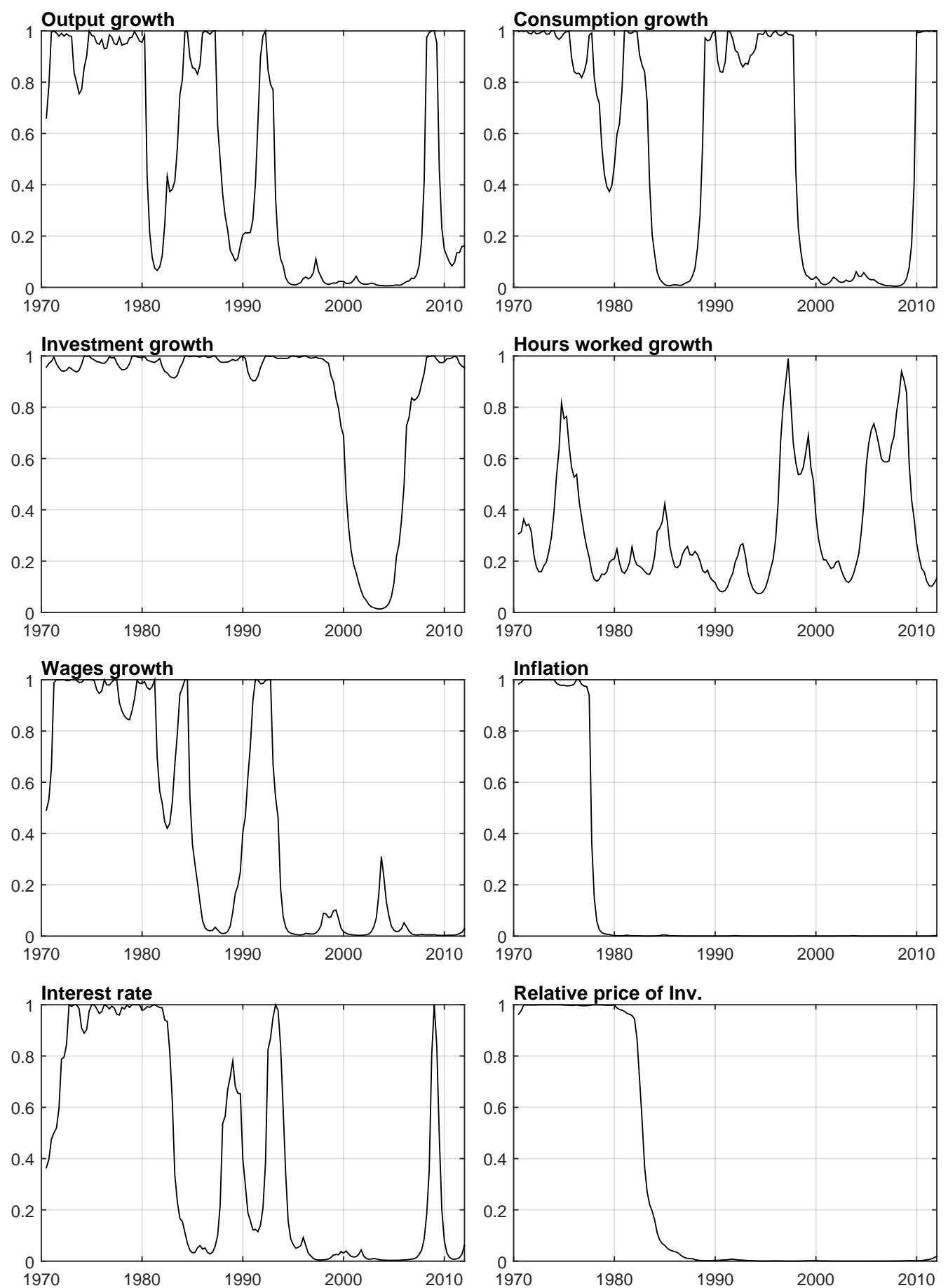

Figure C.2 - Sample period: 1970.Q2-2012.Q1. Smoothed probabilities. 

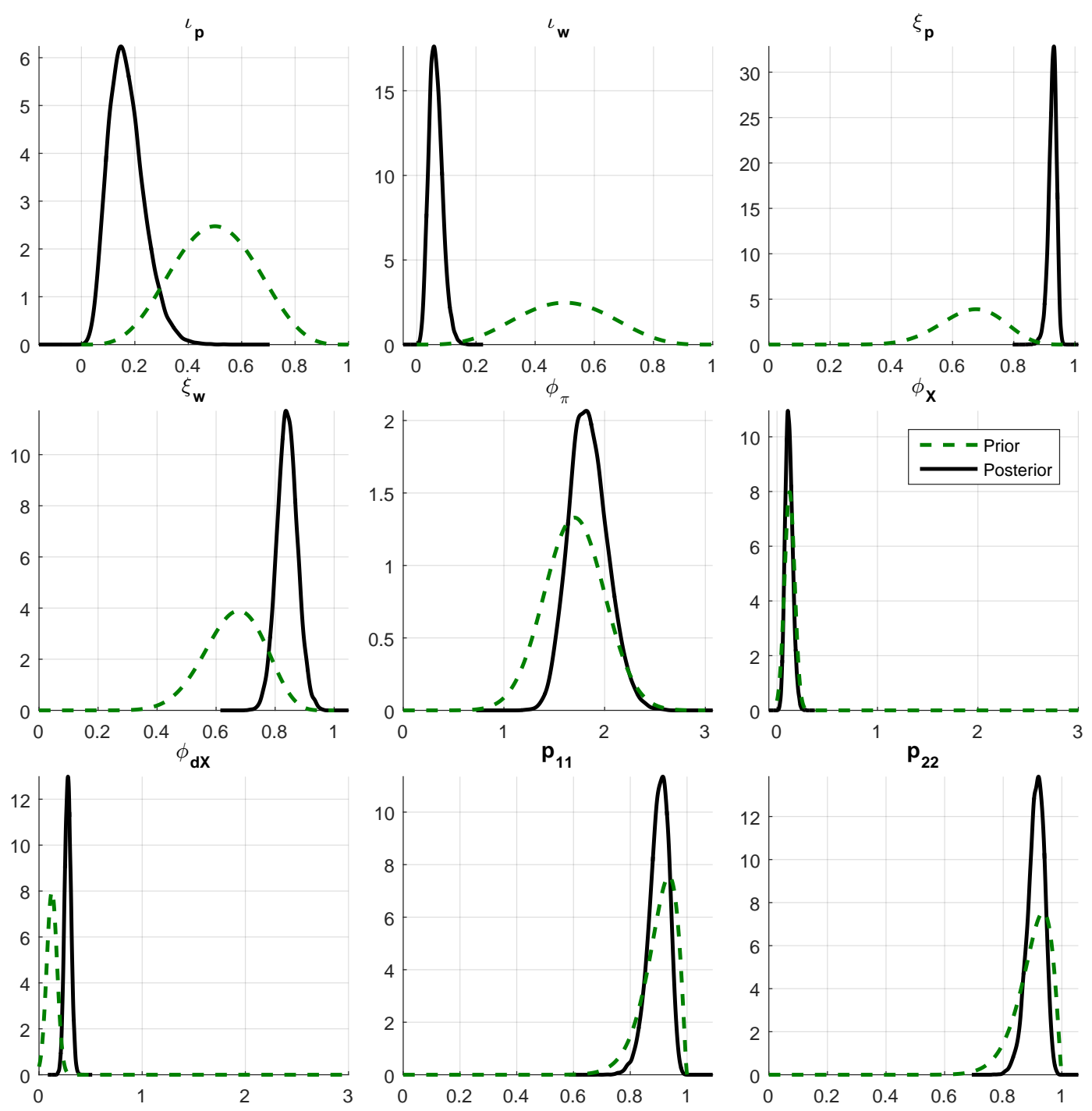

Figure C.3 - Priors and Posteriors of some key parameters. 


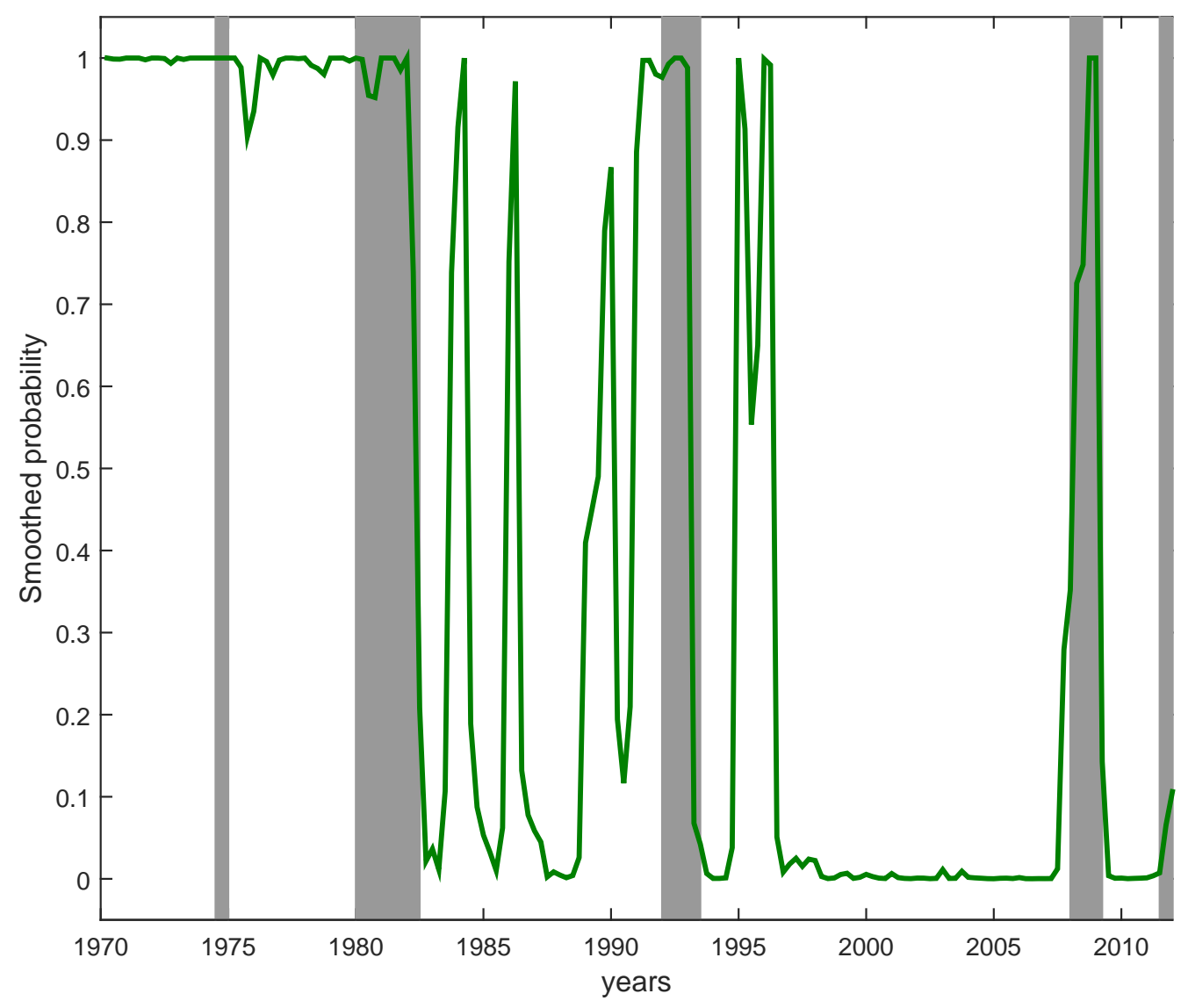

Figure C.4 - Sample period: 1970.Q2-2012.Q1. Smoothed probabilities of the highvolatility regime. The grey areas denote CEPR recessions of the euro area. 


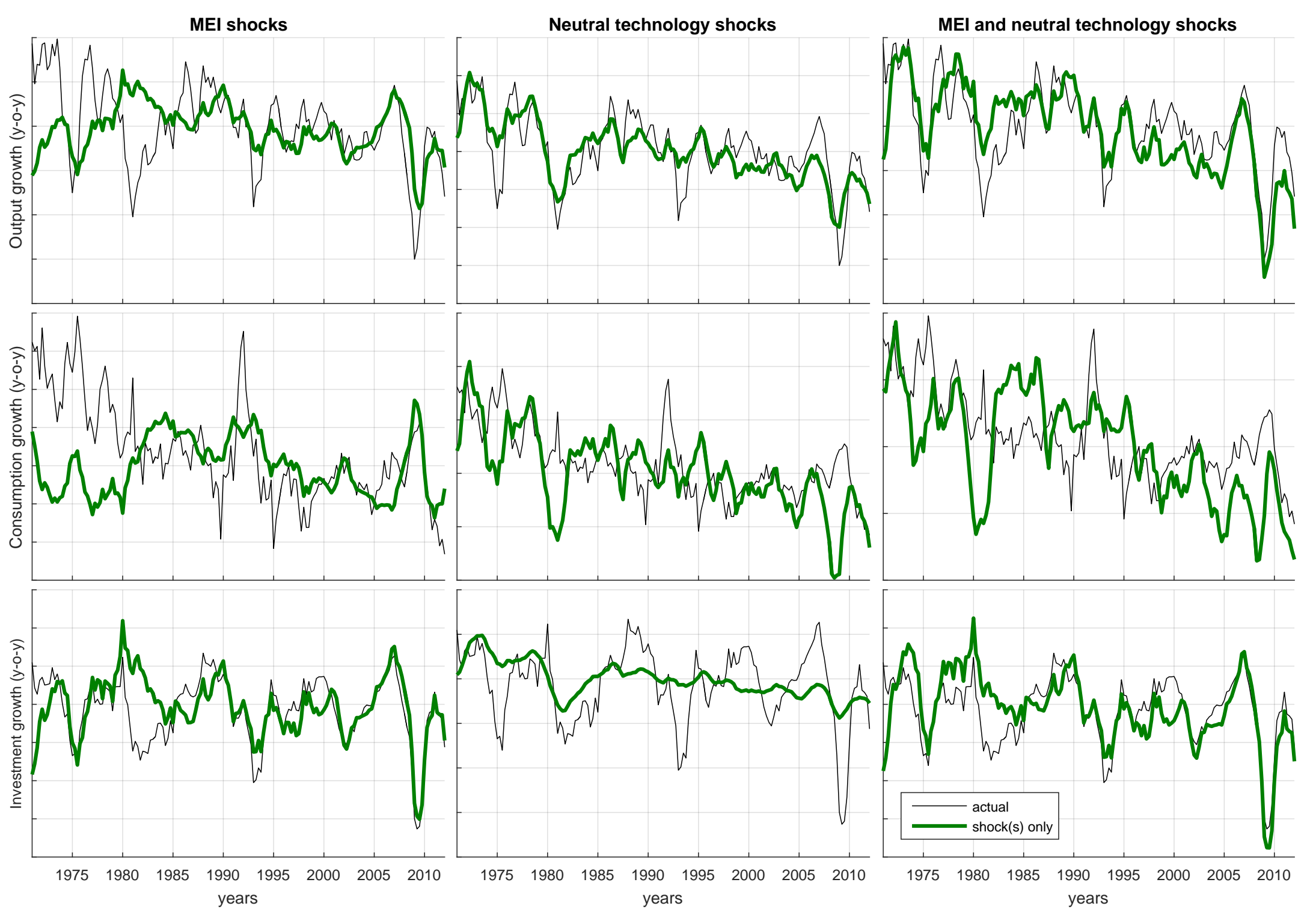

Figure C.5 - Sample period: 1970.Q2-2012.Q1. Actual (black line) and counterfactual series (green line) explained by MEI shocks only (first column), neutral technology shocks only (second column), and the two shocks jointly (third column). The reported series are output growth (first row), consumption growth (second row), and investment growth (third row). All series are annualized. 

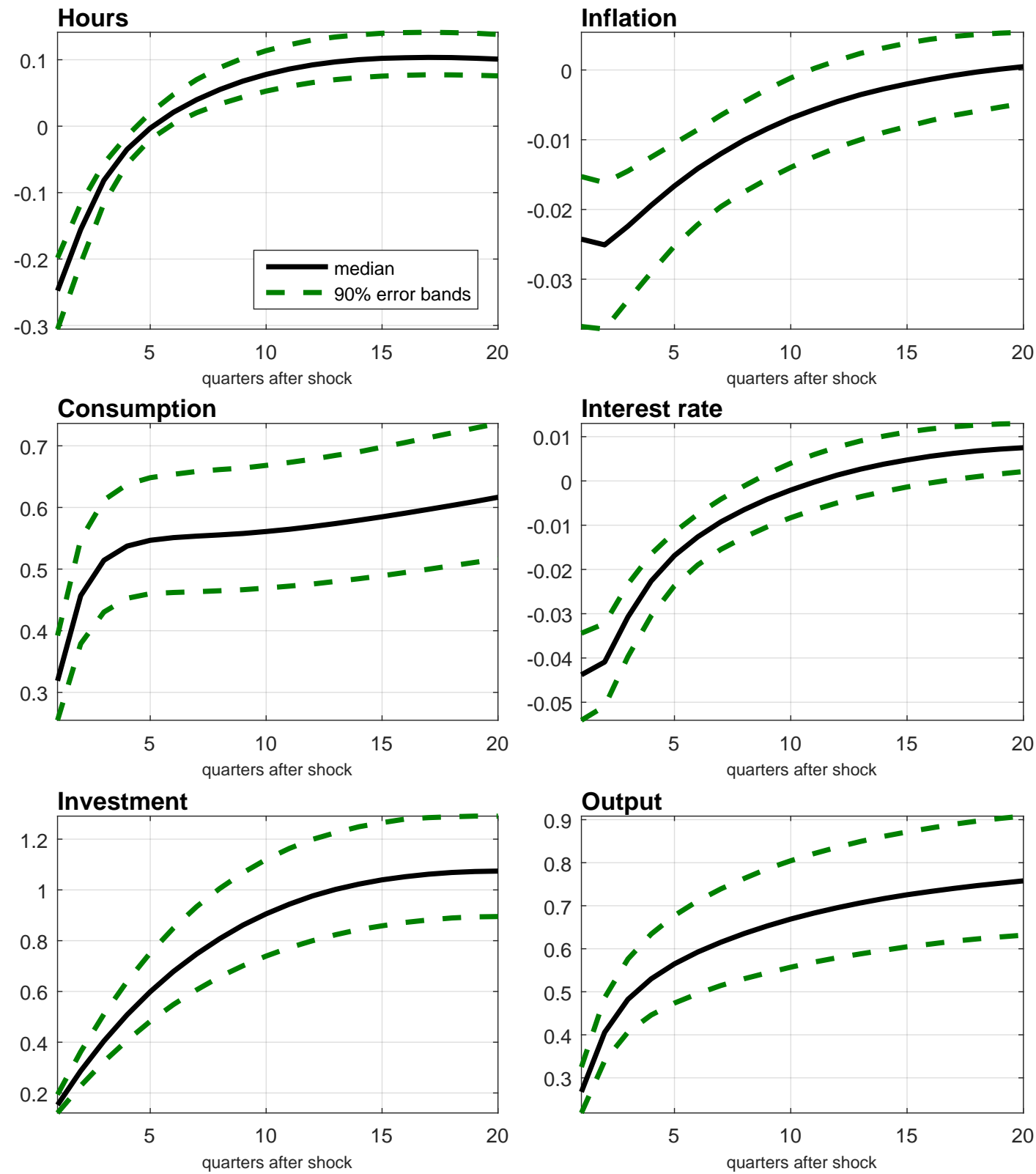

Figure C.6 - Impulse-response functions to neutral technology shock. 

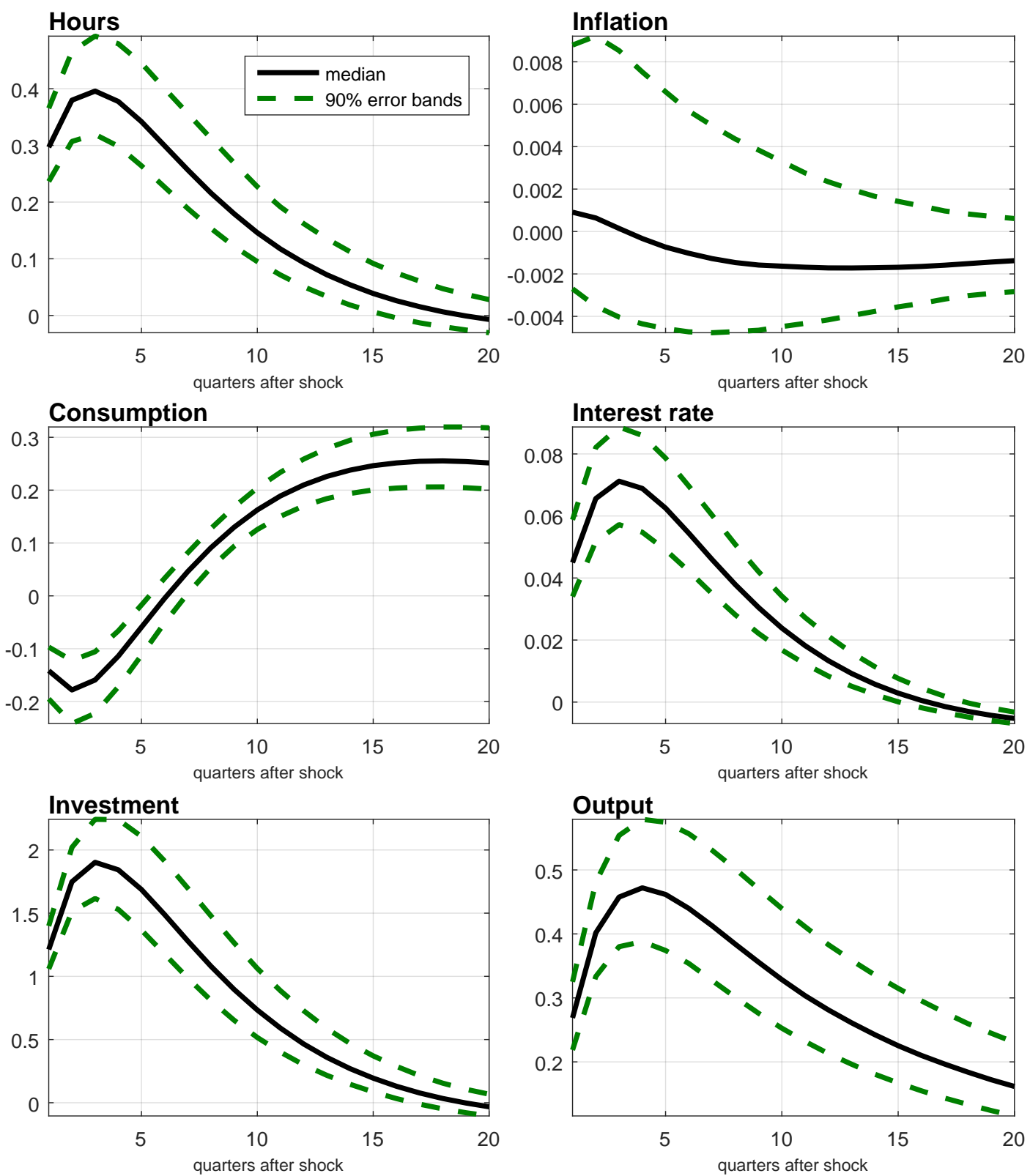

Figure C.7 - Impulse-response functions to MEI shock. 

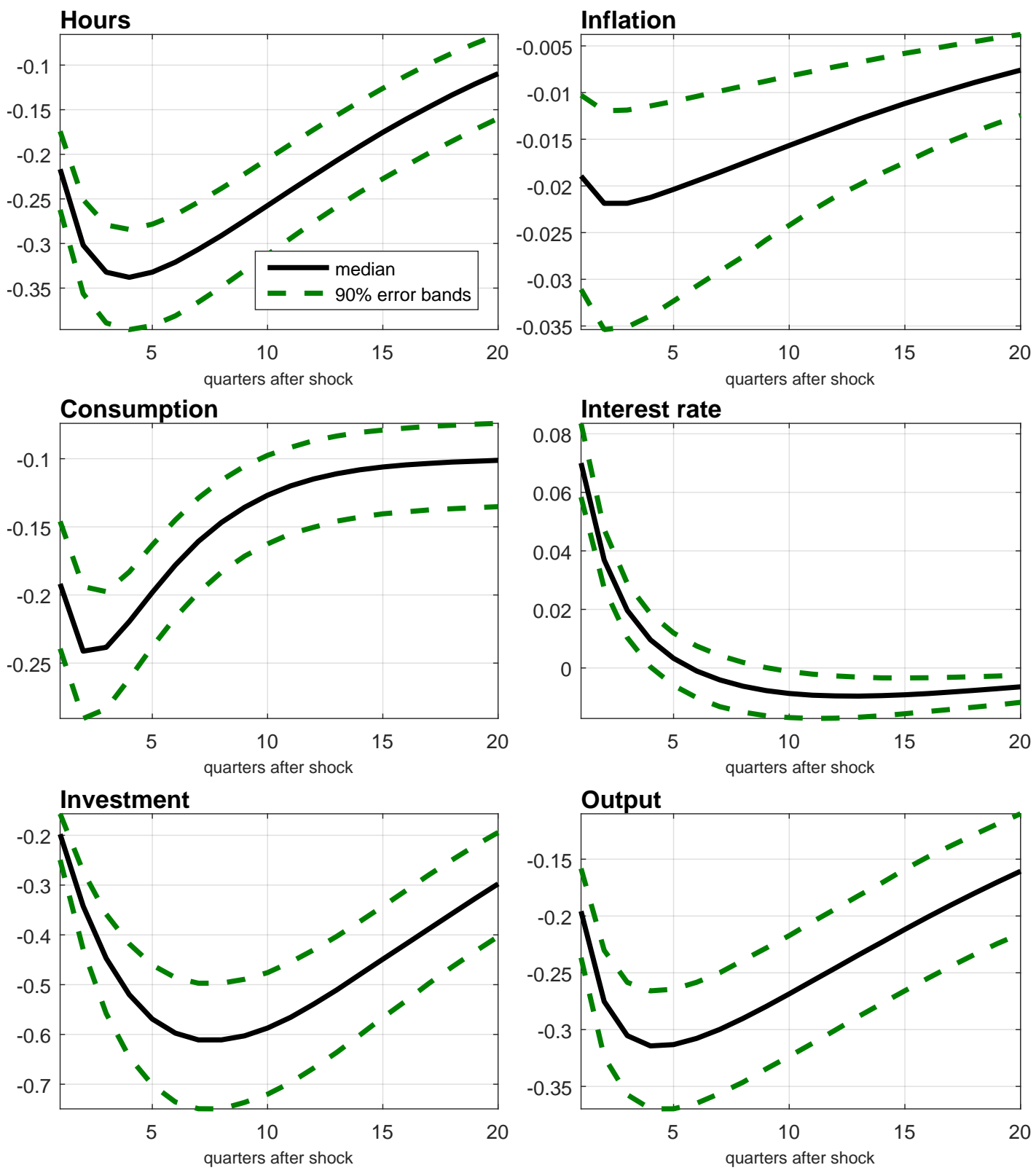

Figure C.8 - Impulse-response functions to monetary policy shock. 


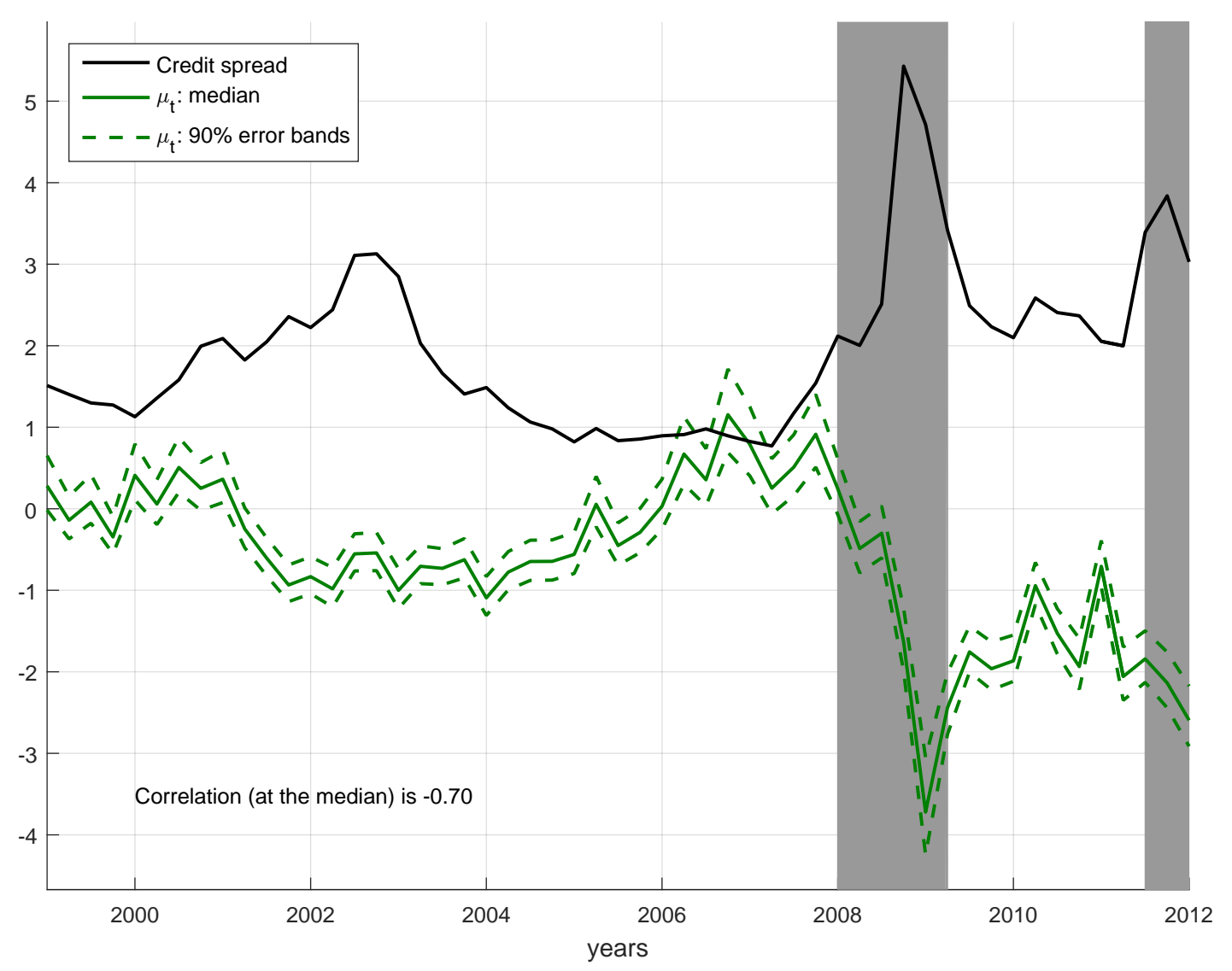

Figure C.9 - Sample period: 1999.Q1-2012.Q1. Non-financial corporate credit spread and the marginal efficiency of investment (MEI). The credit spread is drawn from Gilchrist and Mojon (2014). The marginal efficiency of investment is the time series of the $\mu_{t}$ shock at the posterior median (green line) with the 90 percent probability intervals (green dotted lines). 